\title{
Revealing the reactivity of the Iridium trioxide intermediate for the oxygen evolution reaction in acidic media
}

Paul Pearce, Chunzhen Yang, Antonella ladecola, Juan Rodriguez-Carvajal, Gwenaëlle Rousse, Rémi Dedryvère, Artem M. Abakumov, Domitille Giaume, Michael Deschamps, Jean-Marie Tarascon, Alexis Grimaud

Submitted date: 25/04/2019 - Posted date: 29/04/2019

Licence: CC BY-NC-ND 4.0

Citation information: Pearce, Paul; Yang, Chunzhen; ladecola, Antonella; Rodriguez-Carvajal, Juan; Rousse, Gwenaëlle; Dedryvère, Rémi; et al. (2019): Revealing the reactivity of the Iridium trioxide intermediate for the oxygen evolution reaction in acidic media. ChemRxiv. Preprint.

We report a strategy to isolate $\mathrm{IrO}_{3}$ as an intermediate for the oxygen evolution reaction (OER). Its reactivity is studied using X-ray absorption spectroscopy, X-ray and neutron diffraction and X-ray photoelectron spectroscopy. Its stability is assessed by using on-line mass spectroscopy and inductively coupled plasma optical emission spectroscopy and presented herein. Upon reaction with water in acidic conditions, we could observe the formation of a new protonated iridate phase of composition $\mathrm{H}_{2} \mathrm{IrO}_{3}$. Coupling OER measurements and dissolution rate determination, we could show that its activity and stability are governed by a yet ill-described charge compensation mechanism enlisting reversible bulk proton insertion inside the catalyst structure. This singular property enables an enhanced activity and stability towards dissolution compared to the stellar $\mathrm{IrO}_{\mathrm{x}} / \mathrm{SrlrO}_{3}$ catalyst. Such a finding opens the route towards the design of new OER catalysts enlisting proton insertion that could be competitive for water splitting in acidic media.

File list (2)

Pearce et al - main - ChemRxiv.pdf (1.48 MiB)

view on ChemRxiv - download file

Pearce et al - SI - ChemRxiv.pdf (2.03 MiB)

view on ChemRxiv • download file 


\section{Revealing the reactivity of the Iridium trioxide intermediate for the oxygen evolution reaction in acidic media}

Paul E. Pearce, $\# 1,2,3$ Chunzhen Yang, ${ }^{\# 1,3}$ Antonella ladecola, ${ }^{3}$ Juan Rodriguez-Carvajal, ${ }^{4}$ Gwenaëlle Rousse, ${ }^{1,2,3}$ Rémi Dedryvère, ${ }^{3,5}$ Artem M. Abakumov, ${ }^{6}$ Domitille Giaume, ${ }^{3,7}$ Michael Deschamps, ${ }^{3,8}$ Jean-Marie Tarascon ${ }^{1,2,3,9}$ and Alexis $^{2}$ Grimaud*1,3

The development of efficient water splitting heterogeneous catalysts in acidic media is largely hampered by both the slow kinetics of the oxygen evolution reaction (OER) and the limited stability of the electrocatalyst under these harsh working conditions. At the origin of both the activity and the instability of iridium oxides used as OER catalysts in acid conditions is the formation of high valence $\mathrm{IrO}_{\mathrm{x}}$ intermediates such as IrO $\mathrm{N}_{3}$. Nevertheless, owing to its reactivity with water, this intermediate was never stabilized and its electrochemical/chemical behavior was never studied in depth. Here we report a strategy to stabilize this elusive $\mathrm{IrO}_{3}$ intermediate. Furthermore, we demonstrate that upon reactivity with water, gaseous oxygen is generated while the intermediate is protonated following the reaction $\mathrm{IrO}_{3}+\mathrm{x} \mathrm{H}_{2} \mathrm{O} \rightarrow \mathrm{H}_{2 \mathrm{x}} \mathrm{IrO} \mathrm{O}_{3}+\mathrm{x} / 2 \mathrm{O}_{2}$. The resulting hydrated iridium oxide $\mathrm{H}_{2} \mathrm{IrO} \mathrm{O}_{3}$ which possesses three dimensional proton intercalation/de-intercalation channels can be considered as an enlightening OER model electrocatalyst in acidic media. Owing to its unique proton insertion ability, we could study a yet ill-described charge compensation mechanism upon OER relying on the bulk reversible exchange of protons, which shows remarkable performances and stability. Indeed, enhanced OER is measured, with a dissolution rate lower than the one measured for the "stellar" $\mathrm{IrO}_{x} / \mathrm{SrIrO}_{3}$ catalyst. Such a finding opens the route towards the design of new catalysts enlisting proton insertion that could be competitive for water splitting in acidic media.

\section{Introduction}

Water splitting, the reaction which is at the heart of electrolyzers, plays a key role in renewable energy technologies, ${ }^{1,2}$ but the slow kinetics of the anodic oxygen evolution reaction (OER) largely limits the performances achieved by such energy storage device. ${ }^{3,4}$ Although various transition metal-based oxides and oxyhydroxides have been developed as efficient electrocatalysts for the OER in neutral and alkaline $\mathrm{pH}^{5-10}$ these catalysts seriously corrode in acidic solutions. ${ }^{11-14}$ Hence, to date, iridium oxide $\left({ }^{1} \mathrm{r}_{\mathrm{x}}\right)$ and ruthenium oxide $\left(\mathrm{RuO}_{\mathrm{x}}\right)$ electrocatalysts are widely considered as the best catalysts to work in these harsh conditions. ${ }^{15-18}$ However, they still suffer from substantial dissolution and surface instabilities, making them poor choices for long-term use. $^{11,19,20}$ This calls for the rationalization of the science at play in order to develop new strategies targeting high activity, long-term stability and limited metal dissolution in acidic media.

${ }^{1}$ Chimie du Solide et de l'Energie, UMR 8260, Collège de France, 11 Place Marcelin Berthelot, 75231 Paris Cedex 05, France

${ }^{2}$ Sorbonne Université, 4 place Jussieu, Paris, France

${ }^{3}$ Réseau sur le Stockage Electrochimique de l'Energie (RS2E), CNRS FR 3459, 33 rue Saint Leu, 80039 Amiens Cedex, France

${ }^{4}$ Institut Laue-Langevin, 71 Avenue des Martyrs, CS 20156, 38042, Grenoble, Cedex 9 , France.

${ }^{5}$ IPREM - UMR 5254 CNRS, Université de Pau et des Pays de l'Adour, Hélioparc, 2 Avenue Pierre Angot, 64053 Pau Cedex 9, France

${ }^{6}$ Skoltech Center for Energy Science and Technology, Skolkovo Institute of Science and Technology, Moscow 121205, Russian Federation

${ }^{7}$ Chimie-Paris Tech, PSL Research University, CNRS Institut de Recherche de ChimieParis (IRCP), 75005 Paris, France

${ }^{8}$ CNRS, CEMHTI UPR3079, Universite d'Orleans, 1D avenue de la recherche scientifique, 45071 Orleans Cedex 2, France

${ }^{9}$ ALISTORE-European Research Institute, FR CNRS 3104, 80039 Amiens, France

${ }^{\#}$ Co-first authors

*Correspondence to: alexis.grimaud@college-de-france.fr
Indeed, most materials explored so far as water oxidation electrocatalysts in acidic environment such as $\mathrm{Au}, \mathrm{IrO}_{2}, \mathrm{RuO}_{2}$ or perovskite materials, have demonstrated instability and the formation of an amorphous hydrated $\mathrm{MO}_{\mathrm{x}}$ surface layer after prolonged OER tests. ${ }^{21-29}$ This phenomenon, which is sometimes referred to as self-passivation, is accompanied by cation dissolution. ${ }^{12,30}$ Hence, to suppress the dissolution of precious metals such as Ir, a promising strategy previously investigated is to develop a durable protective surface layer with the formation of a hydrated $\mathrm{IrO}_{\mathrm{x}}$ layer. For example, in a co-catalyst system $\left(I \mathrm{NiO}_{\mathrm{x}}\right), \mathrm{Ni}$ was adopted as a sacrificial metal to be selectively dissolved from the matrix and form an amorphous $\mathrm{IrO}_{\mathrm{x}}$ surface layer. ${ }^{31-33}$ In another catalyst, namely $\mathrm{SrIrO}_{3}$ with the perovskite structure, $\mathrm{Sr}^{2+}$ was selectively dissolved during an activation step thus triggering the formation of a core-shell $\mathrm{IrO}_{\mathrm{x}} / \mathrm{SrIrO}_{3}$ structure. ${ }^{34}$

At the origin of this phenomenon, recent studies revealed the existence of a common intermediate responsible for both the enhanced OER activity for iridium-based catalysts as well as their relative instability: high valence $\mathrm{IrO}_{3}$ formed upon deprotonation/oxidation and which possesses electrophilic oxygen serving as active sites for water to react. ${ }^{35-39}$ These electrophilic oxygen species are highly reactive and undergo nucleophilic attack from water to form O-O bonds, step usually considered as the rate limiting one for OER catalysts. ${ }^{40}$ Therefore, their formation was proposed to be at the origin for the high OER activity measured for hydrated iridium oxide surfaces. Nevertheless, increasing the surface reactivity of oxygen ligands towards water leads to oxygen vacancies formation on the surface of the catalyst and a decrease in the coordination number of the surface transition metals, hence promoting their dissolution into the electrolyte presumably into the form of $\mathrm{IrO}_{4}{ }^{2-}$ species. ${ }^{36,41,42}$ Thus, owing to the 
reactivity of this high valence $\mathrm{IrO}_{3}$ intermediate with water, it could never be isolated and its electrochemical properties studied independently, preventing us from designing new approaches in order to control its activity and stability.

In this work, we have designed a strategy in order to stabilize the $\mathrm{IrO}_{3}$ intermediate and to study its chemical reactivity. For that, the $\beta-\mathrm{Li}_{2} \mid \mathrm{IO}_{3}$ compound previously described as a model Li-ion battery electrode material ${ }^{43}$ was used as a precursor. Electrochemical oxidation/delithiation was then carried out in organic solvent to isolate the fully delithiated $\mathrm{\beta}-\mathrm{IrO}_{3}$ phase, allowing us to study for the first time its chemical reactivity with water as well as its stability. Finally, we demonstrate that a hydrated iridate catalyst $\left(\beta-\mathrm{H}_{2} \mid \mathrm{rO}_{3}\right)$ is eventually formed upon reaction of $\beta-\mathrm{IrO}_{3}$ with water, which upon bulk proton de-intercalation triggers the oxygen redox activity of the catalyst, thus reforming electrophilic oxygens which chemically react with water. This new finding helps us unravel the complex OER mechanisms ${ }^{44}$ for the yet illunderstood amorphous hydrated $\mathrm{IrO}_{\mathrm{x}}$ surface layers.

\section{Results and discussion}

We first prepared different iridium oxide intermediates $\beta$ $\mathrm{Li}_{y} \mathrm{IO}_{3}$ (with $\mathrm{y}$ being $1,0.5$ and 0 ) by the electrochemical delithiation of $\beta-\mathrm{Li}_{2} \mathrm{IrO}_{3}$ in $\mathrm{Li}$-ion half-cells. Indeed, this electrochemical preparation was conducted in organic electrolytes containing no water thus allowing for the formation of these intermediates that could never be stabilized in aqueous conditions. The Ir oxidation states of these phases was first studied by ex situ X-ray absorption spectroscopy (XAS) at the $\operatorname{Ir} \mathrm{L}_{3}$-edge (Figure 1a). While an increase of the white line (WL) energy would indicate the oxidation of iridium upon delithiation, as expected for a classical oxidation event counterbalanced by a cationic redox active center, we instead observed no increase of the WL energy which stays close to the one of $\mathrm{Sr}_{2} \mathrm{FelrO}_{6}$ used as $\mathrm{Ir}^{5+}$ reference. $^{42}$ These XAS measurements at the Ir L-edge were then complemented by ex situ O 1s X-ray photoelectron (XPS) measurements (Figure $1 \mathrm{~b}$ ) which show, in agreement with previous operando results for $\mathrm{IrO}_{\mathrm{x}}$ catalysts, ${ }^{37}$ the formation of oxidized " $\mathrm{O}^{\mathrm{n}-}$ " species after complete delithiation and the formation of $\beta-\mathrm{IrO}_{3}$. These results indicate that the oxidation of $\beta-\mathrm{Li}_{2} \mathrm{IrO} \mathrm{O}_{3}$ is counter-balanced by the redox activity of the oxygen ligand and the oxidation of $\mathrm{O}^{2-}$ to " $\mathrm{O}^{\mathrm{n}-}$ " species for $\beta$ $\mathrm{Li}_{\mathrm{y}} \mathrm{IrO} \mathrm{O}_{3}$ with $\mathrm{y} \leq 1$, following the so-called anionic redox mechanism. ${ }^{43}$ We can therefore confirm that the oxidation of the $\beta-\mathrm{Li}_{2} \mid \mathrm{IO}_{3}$ precursor leads to the formation of electrophilic oxygen species.

The reactivity of the different intermediates $\beta-\mathrm{Li}_{y} \mathrm{IrO}_{3}$ (with $y=1,0.5$ and 0 ) with water was then studied upon exposure to a degassed $1 \mathrm{M} \mathrm{H}_{2} \mathrm{SO}_{4}$ solution. Analyzing the exposed samples by X-ray diffraction (XRD) (Figure $1 \mathrm{c}$ ), $\beta-\mathrm{IrO}_{3}$ and $\beta-\mathrm{Li}_{0.5} \mathrm{IrO} \mathrm{I}_{3}$ are found to be fully transformed into a new phase. Concomitantly, similar energies of the $\mathrm{WL}$ at the $\operatorname{Ir} \mathrm{L}_{3}$-edge and therefore similar oxidation states comprised between $\operatorname{~r~}^{5+}$ and $\operatorname{Ir}^{4+}\left(\mathrm{Ir}^{4+} \mathrm{O}_{2}\right)$ were found by XAS after exposure to $\mathrm{H}_{2} \mathrm{SO}_{4}$ for these two samples (Figure 1a), indicative of their spontaneous reduction when in contact with acidic media. Furthermore, this chemical reactivity is dependent on the oxidation state of the catalyst and $\beta-\mathrm{Li}_{1} \mid \mathrm{IO}_{3}$ was found by XRD to be only partially transformed into this new phase (Figure $1 \mathrm{c}$ ) while its oxidation state was found greater than the one measured for $\beta-\mathrm{IrO}_{3}$ and $\beta-\mathrm{Li}_{0.5} \mathrm{IrO}_{3}$ after soaking (Figure $1 \mathrm{a}$ ). Finally, XPS analysis shows after reacting $\beta-\mathrm{IrO}_{3}$ with $\mathrm{H}_{2} \mathrm{SO}_{4}$ the apparition of a new $\mathrm{O}$ 1s peak at $531.4 \mathrm{eV}$ which corresponds to the formation of $\mathrm{OH}^{-}$ species (Figure 1b). ${ }^{37,41,45}$ Note that the $\mathrm{O} / \mathrm{Ir}$ ratio is constant for $\beta-\mathrm{Li}_{2} \mathrm{IrO}_{3}, \beta-\mathrm{IrO}_{3}$ and $\beta$-IrO $\mathrm{IO}_{3}$ exposed to $\mathrm{H}_{2} \mathrm{SO}_{4}$ if we take into account only the colored $\mathrm{O} 1 \mathrm{~s}$ components, which proves that these colored components are due to oxygen atoms bound to iridium while the others are surface species. Therefore, while the presence of residual $\mathrm{O}^{\mathrm{n}-}$ oxygen cannot be excluded in $\beta$ IrO $\mathrm{r}_{3}$ after exposure to $\mathrm{H}_{2} \mathrm{SO}_{4}$ due to energy resolution of the spectrum, their overall weight has largely decreased upon reduction, suggesting their participation to the charge balance process. 

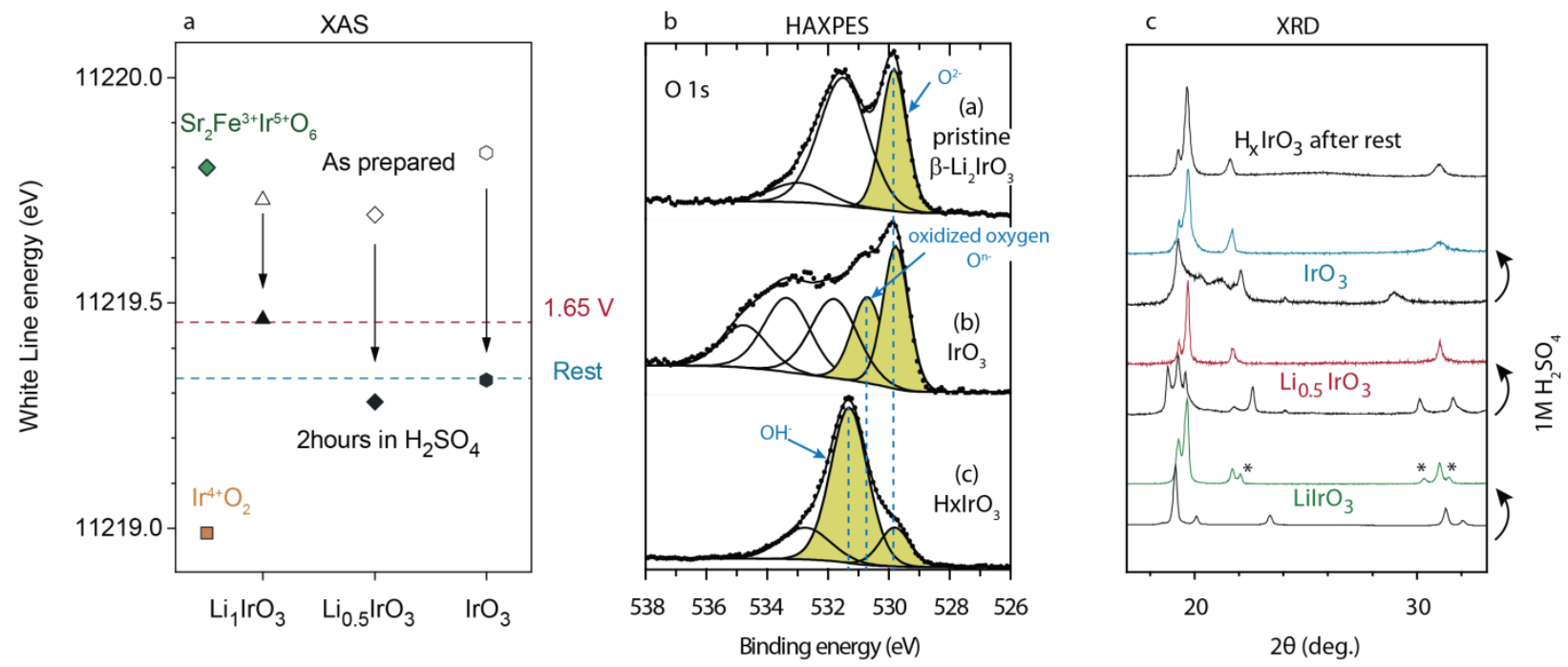

Figure 1 Chemical reactivity of oxidized $\beta-\mathrm{Li}_{2} \mid \mathrm{IO}_{3}$ with acid. a) Evolution of the WL energy position of the Ir $\mathrm{L}_{3}$-edge XAS for the different compounds before (open symbols) and after acid treatment (filled symbols). $\mathrm{IrO}_{2}$ (orange square) and $\mathrm{Sr}_{2} \mathrm{FelrO}_{6}$ (green diamond) are shown as references for $\mathrm{Ir}^{+\mathrm{IV}}$ and $\mathrm{Ir}^{+\mathrm{V}}$, respectively. b) $\mathrm{O} 1 \mathrm{~s} \mathrm{X}$-ray photoelectron spectra with the pristine $\beta-\mathrm{Li}_{2} \mid \mathrm{IO}_{3}$ phase (top), the fully delithiated $\mathrm{IrO}_{3}$ phase (middle) and $\mathrm{IrO}_{3}$ after exposure to $1 \mathrm{M} \mathrm{H}_{2} \mathrm{SO}_{4}$ solution (bottom). The stars indicate surface adsorbed or deposited species. Colored areas indicate oxygen atoms bound to iridium. In order to decrease the intensity of surface components, spectrum (b) was recorded with $6900 \mathrm{eV}$ photon energy on the GALAXIES beamline at the SOLEIL synchrotron (multiplying the probe depth by 4.5). Other spectra were recorded with 1487 eV (standard XPS). c) XRD patterns for each compound before (black) and after acid treatment (colored line) compared to the XRD pattern collected after rest for $\beta_{-} \mathrm{H}_{x} \mid \mathrm{I} \mathrm{O}_{3}$.

While the oxidized active form of the catalyst is reduced in contact with acid, we could demonstrate using online mass spectrometry (OMS) that this reduction is concomitant with the oxidation of water. Indeed, when exposing $\beta-\mathrm{IrO}_{3}$ and $\beta$ $\mathrm{Li}_{0.5} \mathrm{IO}_{3}$ to $1 \mathrm{M} \mathrm{H}_{2} \mathrm{SO}_{4}$, gaseous oxygen is found to be chemically evolved (Figure 2a). Interestingly, the amount of oxygen evolved is dependent on the oxidation state of the iridium oxide, with the more oxidized form of the catalyst $\left(\beta-1 \mathrm{IO}_{3}\right)$ generating the most oxygen. Almost no oxygen is evolved when exposing $\beta-\mathrm{Li}_{1} \mid \mathrm{IO}_{3}$ to $\mathrm{H}_{2} \mathrm{SO}_{4}$. This observation can be rationalized when observing that the redox potentials for the formation of $\beta-\mathrm{IrO}_{3}$ and $\beta-\mathrm{Li}_{0.5} \mathrm{IrO}_{3}$ (respectively 4.55 and $4.4 \mathrm{~V}$ vs. $\left.\mathrm{Li}^{+} / \mathrm{Li}\right)$ are above the reversible potential for water oxidation at $\mathrm{pH} 0\left(4.27 \mathrm{~V}\right.$ vs. $\mathrm{Li}^{+} / \mathrm{Li}$, Figure S1). In contrast, the redox potential for $\beta-\mathrm{Li}_{1} \mid \mathrm{IO}_{3}$ is below the OER potential at $\mathrm{pH} 0$ (3.4 V vs. $\mathrm{Li}^{+} / \mathrm{Li}$, Figure S1) and therefore it does not chemically oxidize water. Hence, $\beta-\mathrm{IrO}_{3}$ and $\beta-\mathrm{Li}_{0.5} \mathrm{IrO}_{3}$ are unstable in acidic conditions, therefore acting as an oxidizing agent while $\mathrm{H}_{2} \mathrm{O}$ acts as a reducing agent, giving the overall reaction: $\mathrm{IrO}_{3}+$ $\mathrm{H}_{2} \mathrm{O} \rightarrow \mathrm{H}_{2} \mathrm{IrO}_{3}+1 / 2 \mathrm{O}_{2}$ (see discussion below for the formation of $\left.\mathrm{H}_{2} \mid \mathrm{rO}_{3}\right)$. The amount of oxygen generated during this chemical redox reaction is governed by the oxidizing power of the iridium oxide, which is function of the oxidation state and the concentration of active form of the catalyst itself given by the amount of protons in the phase. In other words, the difference between the redox potential of the iridium oxide and $\mathrm{E}\left(\mathrm{O}_{2} / \mathrm{H}_{2} \mathrm{O}\right)$ acts as the driving force for the water oxidation.

Bearing in mind that electrophilic " $\mathrm{O}$ "-” oxygen species were previously reported to be responsible for both the activity and the instability of Ir-based oxides used as OER catalysts, ${ }^{25,37}$ we then measured by inductively coupled plasma - optical emission spectrometry (ICP-OES) the amount of Ir- leached out during the chemical reactivity of each intermediate with a solution of $1 \mathrm{M} \mathrm{H}_{2} \mathrm{SO}_{4}$ (Figure $2 \mathrm{~b}$ ). For the pristine $\beta-\mathrm{Li}_{2} \mathrm{IrO} \mathrm{O}_{3}$ compound, a negligible amount of $\mathrm{Ir}$ was found leached out during soaking in acid and this amount is found to increase when oxidizing the material from $\beta-\mathrm{Li}_{2} \mid \mathrm{IO}_{3}$ to $\beta-\mathrm{IO}_{3}$. Hence, combining these results with the OMS results previously discussed, we can confirm that the formation of electrophilic " $\mathrm{O}^{\mathrm{n}-\text { " }}$ oxygen species results in an increased reactivity of the surface and the dissolution of iridium. Moreover, we could relate this iridium dissolution to the surface instability often observed on the surface of crystalline iridium-based oxides using high resolution transmission electron microscopy (HR-TEM). Indeed, the HRTEM images of $\beta$-IrO $\mathrm{O}_{3}$ exposed to a $1 \mathrm{M} \mathrm{H}_{2} \mathrm{SO}_{4}$ solution revealed the presence of a thin amorphous surface layer (Figure 2c). In summary, electrophilic " $\mathrm{O}^{\mathrm{n}-\iota}$ oxygen species are formed by the electrochemical oxidation of the iridium oxide catalyst before being consumed by the chemical reaction with $\mathrm{H}_{2} \mathrm{O}$, leading to the formation of hydroxyl groups, as observed by XPS (Figure 1b). This protonation reduces the oxidation state of the iridium oxide and reduces the dissolution of iridium, as the ICP-OES results reveal when comparing the dissolution rate found for $\beta-\mathrm{IrO}_{3}$ and $\beta-\mathrm{H}_{2} \mathrm{IrO}_{3}$ (Figure $2 \mathrm{~b}$ ).

In order to better understand the bulk phase transformation previously spotted by ex situ XRD (Figure 2c), operando XAS and XRD measurements were employed to monitor the electrochemical oxidation of $\beta-\mathrm{Li}_{2} \mathrm{IrO}_{3}$ in $1 \mathrm{M}$ $\mathrm{H}_{2} \mathrm{SO}_{4}$. Starting from $\beta-\mathrm{Li}_{2} \mid \mathrm{IO}_{3}$, several redox processes can be observed below the OER potential (below $\approx 1.55 \mathrm{~V}$ vs. RHE, Figure 3a). A chemometric approach based on Principal Component Analysis (PCA) and Multivariate Curve Resolution Alternating Least Squares (MCR-ALS) ${ }^{46,47}$ was applied to the whole XAS data collected during the anodic scan (Figure $3 \mathrm{~b}$, 
a

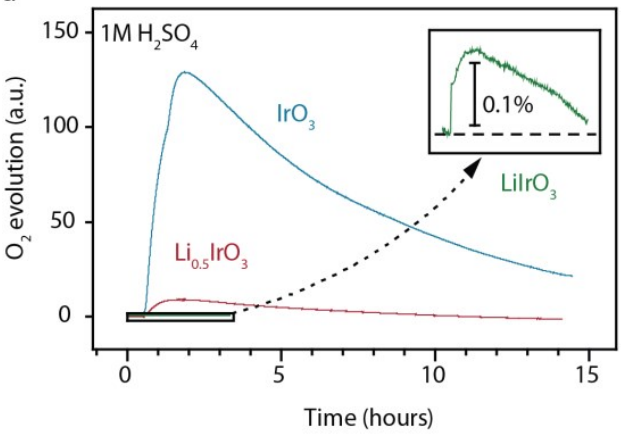

b

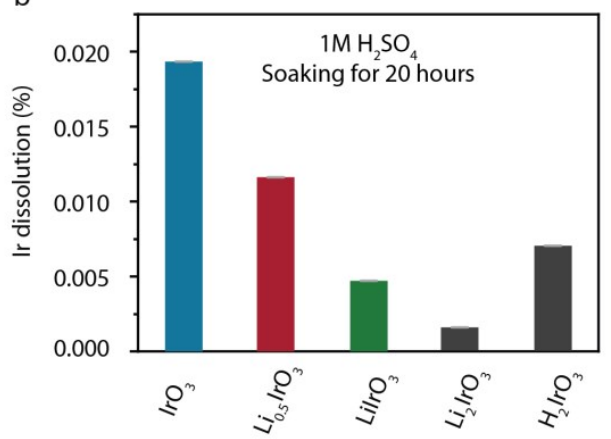

C

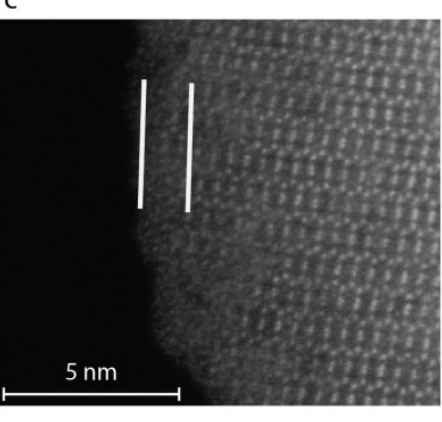

Figure 2 Chemical reactivity of different oxidized $\beta$ - $\mathrm{Li}_{2} \mathrm{IO}_{3}$ intermediates with acid. a) On-line mass spectrometry for $\beta$-IrO $\mathrm{IO}_{3}, \beta$ - $\mathrm{Li}_{0.5} \mathrm{IrO} \mathrm{O}_{3}$ and $\beta$ - $\mathrm{Lil} \mathrm{IO}_{3}$ upon chemical exposure to $1 \mathrm{M}$ $\mathrm{H}_{2} \mathrm{SO}_{4}$. b) Ir dissolution measured by ICP-OES after soaking the different intermediate phases in a solution of $1 \mathrm{M} \mathrm{H} \mathrm{H}_{2} \mathrm{SO}_{4}$. c) HAADF-STEM image along the [110] zone axis of the resulting protonated iridate phase.

middle). Four components are necessary in order to fully describe the oxidation process as suggested by PCA; the evolution of their concentration profiles was obtained by MCRALS method and is given in Figure $3 \mathrm{~b}$. First, the pristine $\beta$ $\mathrm{Li}_{2} \mathrm{IO}_{3}$ phase disappears below $1.4 \mathrm{~V}$ vs. RHE while a second component appears. This second component then disappears between 1.4 and $1.65 \mathrm{~V}$ vs. RHE where a third one grows. Finally, when holding the electrode at $1.65 \mathrm{~V}$ for an hour, a fourth and final component is completely formed. Since no appropriate XAS references were found to assign these phases, operando XRD was then performed under the same conditions (Figure $3 b$, right). Analyzing the structural modifications, the second phase can be attributed to the partially delithiated $\beta-$ $\mathrm{Li}_{1} \mathrm{IO}_{3}$ phase, while the third phase does not correspond to the $\beta-\mathrm{Li}_{0.5} \mathrm{IrO}_{3}$ normally formed when oxidizing $\beta-\mathrm{Li}_{1} \mid \mathrm{IO}_{3}$ in organic electrolyte. ${ }^{43}$ Finally, a final phase grows when holding the electrode at $1.65 \mathrm{~V}$ vs. RHE. During the second anodic scan, the oxidation events previously observed below the OER potential are drastically modified while the OER activity is found stable (Figure 3a), indicating that a stable regime is reached. Overall, this investigation confirms that the high valence $\mathrm{IrO}_{3}$ intermediate cannot be isolated in aqueous solution and reveals that the whole bulk of $\beta-\mathrm{Li}_{y} \mid \mathrm{IO}_{3}$ is transformed concomitantly with the OER process.

To single out the phase newly formed by reaction of delithiated $\beta-\mathrm{Li}_{y} \mathrm{IrO} \mathrm{O}_{3}(\mathrm{y} \leq 0.5)$ with acid, $\beta-\mathrm{Li}_{2} \mid \mathrm{IO}_{3}$ was reacted under hydrothermal conditions in $1 \mathrm{M} \mathrm{H}_{2} \mathrm{SO}_{4}$ at $120^{\circ} \mathrm{C}$ (see methods). Doing so, a phase with a similar XRD pattern when compared to the phase previously observed after reaction of $\beta-\mathrm{Li}_{y} \mid \mathrm{IO}_{3}(\mathrm{y} \leq 0.5$ ) with acid (Figure $1 \mathrm{c}$ and Figure $3 \mathrm{~b}$ ) is formed, confirming that both reaction pathways lead to the formation of a similar phase. The structure of the as-synthetized compound was first refined by synchrotron XRD and found to possess a $3 \mathrm{D} \beta-\mathrm{IrO}_{3}$ scaffold with the $\mathrm{Fddd}$ space group similar to its lithium parent phase ${ }^{43}$ (Figure $4 a$ and $4 b$ and Table S1 of the supplementary information). In order to determine the chemical composition of the as-prepared phase, thermogravimetric analysis (TGA) was carried out, in which two significant mass losses can be observed (Figure 4d). The first process starting at around $300^{\circ} \mathrm{C}$ is associated with a 7.3 w\% loss. Coupling TGA with mass spectrometry, this loss could be attributed to the removal of $\mathrm{H}_{2} \mathrm{O}$ and the formation of $\mathrm{IrO}_{2}$, as deduced by ex situ XRD (Figure 4e). Starting at $900^{\circ} \mathrm{C}$, a second mass loss $\left(\approx 13 \mathrm{w} \%\right.$ ) corresponding to the release of $\mathrm{O}_{2}$ and the formation of metallic $\mathrm{Ir}$ is observed. From these measurements, the composition for the newly formed phase can be determined to be $\beta-\mathrm{H}_{2} \mid \mathrm{rO}_{3}$ and the presence of protons in the bulk of the phase was further confirmed by ${ }^{1} \mathrm{H}$ solid state nuclear magnetic measurements (Figure S2). Finally, the positions of structural protons were determined by refining the neutron powder diffraction (NPD) pattern using the Rietveld method (Figure $4 \mathrm{c}$ and Table S2). Two different positions were found: one forming hydroxyl groups with an O$\mathrm{H}$ bond length of 1.091(6) $\AA$ and the other forming $\mathrm{H}_{2} \mathrm{O}$ groups with an $\mathrm{O}-\mathrm{H}$ bond length of 1.043(11) $\AA$ and an $\mathrm{H}-\mathrm{O}-\mathrm{H}$ angle of $103.3(6)^{\circ}$, close to that of free water (Figure $4 \mathrm{f}$ ).

Having established that $\beta-\mathrm{Li}_{x} \mathrm{IrO}_{3}$ transforms into a new protonated phase $\beta-\mathrm{H}_{2} \mid \mathrm{IO}_{3}$ during oxidation in acidic conditions, the question then arises regarding the redox and structural activity of this protonated phase during OER. To track down the structural evolution of the $\beta-\mathrm{H}_{2} I \mathrm{IO}_{3}$ phase upon OER, operando XRD was carried out during the anodic scan in 1

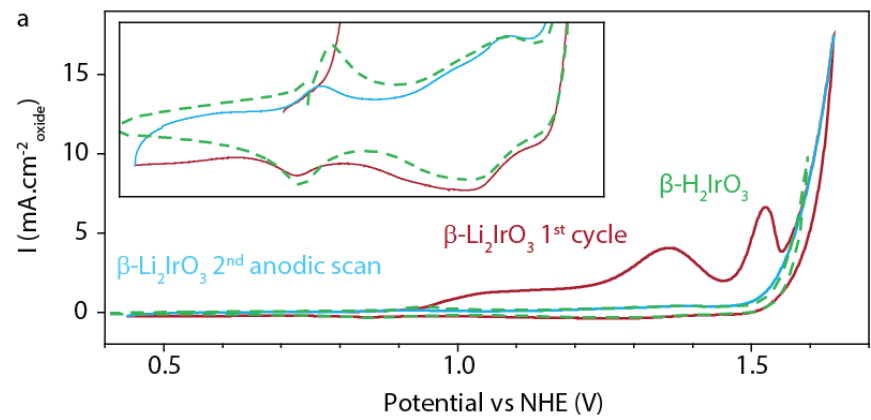

b

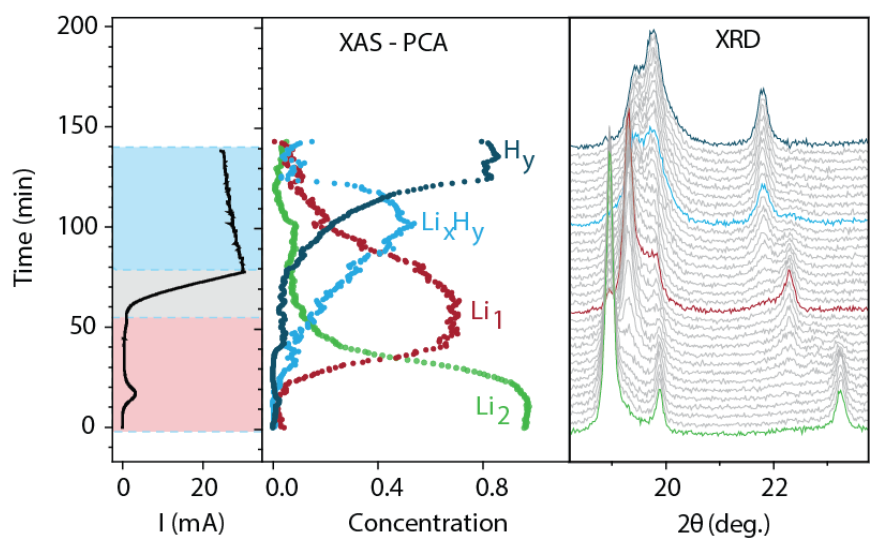

Figure 3 a) Cyclic voltammetry for the $\beta-\mathrm{Li}_{2} \mid \mathrm{IO}_{3}$ in $1 \mathrm{M} \mathrm{H}_{2} \mathrm{SO}_{4}$ (orange) with subsequent anodic scan (blue) compared to the cyclic voltammogram of the $\beta-\mathrm{H}_{2} \mid \mathrm{rO}_{3}$ catalyst (red). (b) Electrochemical profile during anodic scan starting from $\beta-\mathrm{Li}_{2} \mid \mathrm{IO}_{3}$ (left), concentration profiles from the chemometric approach on the operando XAS data (center) and the operando XRD under the same conditions (right). 

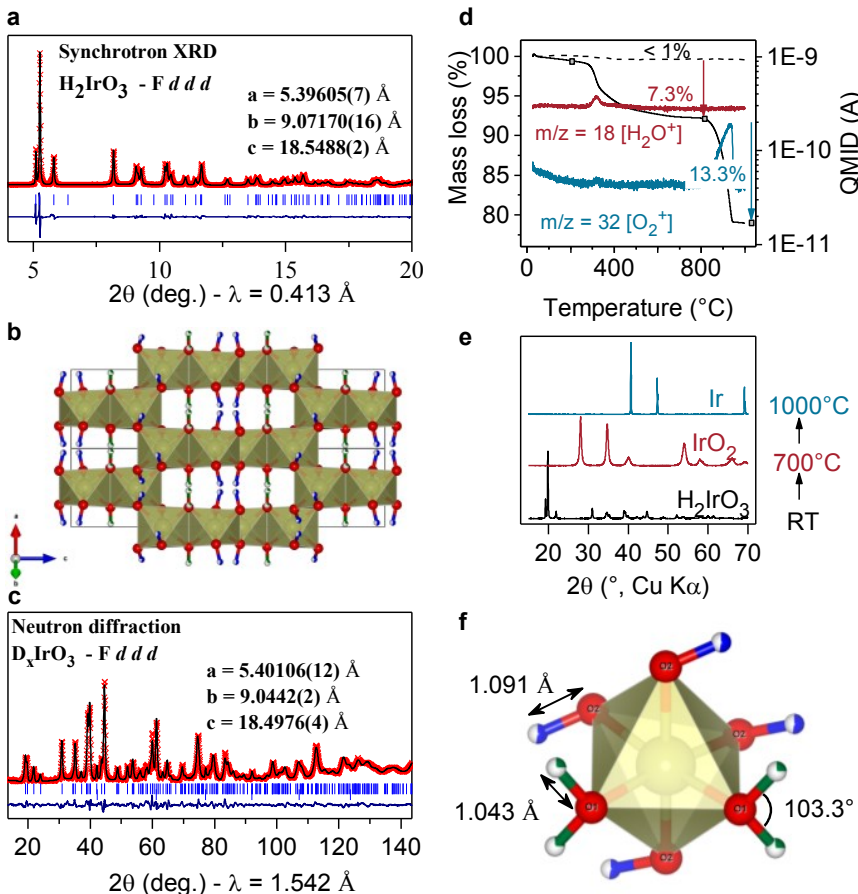

$2 \theta\left({ }^{\circ}, \mathrm{Cu} \mathrm{K} \alpha\right)$

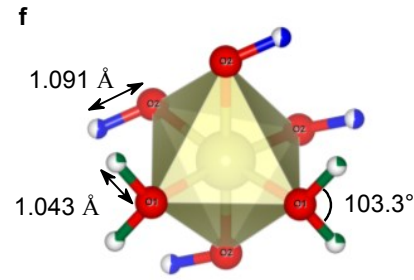

Figure 4 Crystallographic structure of the $\beta-\mathrm{H}_{2} \mid \mathrm{IO}_{3}$ catalyst. (a) Rietveld refinement of synchrotron XRD data for $\beta-\mathrm{H}_{2} \mid \mathrm{IO}_{3}$ with in red the experimental points, in black the calculated pattern, in blue the difference between observed and calculated and the blue ticks are the Bragg reflections. (b) View of the structure along the [110] axis. (c) Rietveld refinement of the neutron powder diffraction data of $\beta-\mathrm{H}_{2} \mid \mathrm{IO}_{3}$ with in red the experimental points, in black the calculated pattern, in blue the difference between observed and calculated and the blue ticks are the Bragg reflections. (d) Thermogravimetric analysis with mass spectrometry data during TGA showing the evolution of $\mathrm{m} / \mathrm{z}=18$ and 32 corresponding to $\mathrm{H}_{2} \mathrm{O}$ (orange) and $\mathrm{O}_{2}$ (blue) respectively. (e) X-ray diffraction patterns of $\beta-\mathrm{H}_{2} \mid \mathrm{IO}_{3}$ pristine (in black), after heating to $700^{\circ} \mathrm{C}$ under $\mathrm{Ar}$ (in orange) and after heating to $1000^{\circ} \mathrm{C}$ under $\mathrm{Ar}$ (in blue). (f) A close up view of an $\mathrm{IrO}_{6}$ octahedra with the two proton positions ( $\mathrm{H} 1$ in blue and $\mathrm{H} 2$ in green).

$\mathrm{M} \mathrm{H}_{2} \mathrm{SO}_{4}$ solution (Figure $5 \mathrm{a}$ and b). Scanning from the OCV to $1.65 \mathrm{~V}$ vs. RHE at $0.2 \mathrm{mV} / \mathrm{s}$, no drastic structural evolution is observed with the exception of a slight shift of the (004) Bragg diffraction peak to lower angle. This is consistent with the low amount of protons extracted during the three redox processes below the OER region (See calculation in Figure S3). Nevertheless, when holding the potential in the OER region at $1.65 \mathrm{~V}$ vs. RHE over 30 minutes, a structural change occurs with the disappearance of the (004) Bragg peak at $19.3^{\circ}$ concomitant with the apparition of a new peak at higher angle $\left(\approx 19.45^{\circ}\right)$ (arrows in Figure $\left.5 b\right)$ and a shift of the main (111) diffraction peak to greater angle. This new phase can be described in the same space group as the pristine $\beta-\mathrm{H}_{2} \mid \mathrm{IO}_{3}$, with nevertheless a modification of the lattice parameters and especially a reduction of the $c$ parameter from $18.523(2) \AA$ to 18.403(3) $\AA$. This observation implies that a structural transformation happens upon the course of the anodic process and shows that the deprotonation/oxidation process occurs during oxidation not only on the surface but also in the bulk of the hydrated Ir oxide phase.
Operando XAS measurements at the Ir $\mathrm{L}_{3}$-edge using an operando cell shown in Figure S4, were then performed to track down changes in bulk oxidation state of the protonated iridium catalyst during OER (Figure $5 c$ and $d$ ). The experiment consists in stepping every five minutes the potential from open circuit voltage (OCV) to $1.65 \mathrm{~V}$ vs. RHE while monitoring for each step changes of the WL energy for the $\operatorname{Ir} L_{3}$-edge (see the full cycle and XANES data in Figure S5). During this procedure, a shift of the WL position at higher energy is observed, indicative of the bulk oxidation of the phase all along the preOER region as well as when entering into the OER potential. Nevertheless, when resting the catalyst at the end of the anodic scan at $1.65 \mathrm{~V} v \mathrm{vs}$. RHE, not only is the potential found to decay towards a value close to $1.3 \mathrm{~V}$ vs. RHE, but a continuous and slight shift of the WL towards lower energy is recorded. This behavior is indicative of the reactivity of the intermediate phase generated at high potential ( $1.65 \mathrm{~V}$ vs. RHE) during OER which is slowly reduced when left in contact with the acidic solution via either proton insertion or decomposition, the former being the most likely owing to the evidences of structural transition as demonstrated below.

These two measurements demonstrate that while the amorphous layer formed on the surface of $\beta-\mathrm{H}_{2} \mid \mathrm{IO}_{3}$ is presumably responsible for the electrocatalytic behavior of this new catalyst (Figure $2 \mathrm{c}$ ), the bulk participates to the overall charge balance process. Indeed, the $\beta-\mathrm{H}_{2} \mid \mathrm{IO} \mathrm{O}_{3}$ phase is gradually deprotonated and oxidized before to reach the OER potential. In fact, our operando measurements reveal that the bulk participates to the overall charge balance upon OER with proton diffusing in and out of the phase to counter balance the reactivity of the surface with water in acidic conditions.
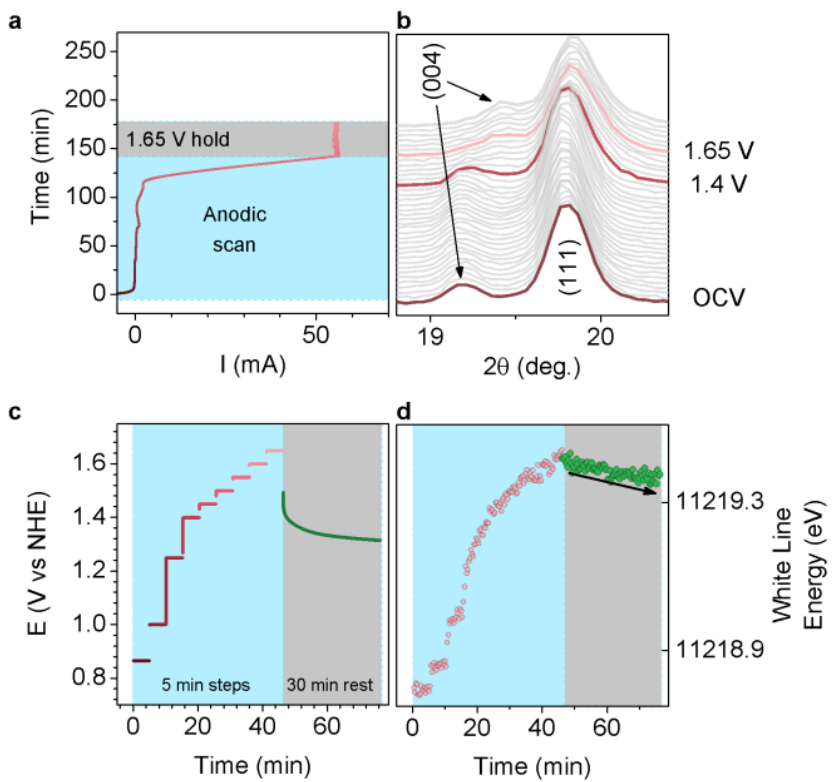

Figure 5 Oxidation process for $\beta-\mathrm{H}_{2} \mid \mathrm{IO}_{3}$. a) time dependence and b) structural evolution as characterized by operando XRD during OER with corresponding electrochemical curve $t=f(I)$. c) Applied potential steps during XAS measurement starting at OCV.The first three steps correspond to the redox peak potentials and from $1.4 \mathrm{~V}$ to $1.65 \mathrm{~V}$, the steps are evenly spaced by $50 \mathrm{mV}$. d) The evolution of the WL energy position of the Ir $\mathrm{L}_{3}$-edge extracted from the operando XAS data. 
Having determined that structural protons are reversibly exchanged between $\beta-\mathrm{H}_{2} \mid \mathrm{rO}_{3}$ and the electrolyte during 1 ) the pre-activation step consisting of the deprotonation of the catalyst and 2) the chemical reaction of the active form of the catalyst with water, the electrochemical OER activity of $\beta$ $\mathrm{H}_{2} \mathrm{IrO}_{3}$ was then compared with the state-of-the-art $\mathrm{IrO}_{2}$ and $\mathrm{IrO}_{\mathrm{x}} / \mathrm{SrIrO}_{3}$ electrocatalysts (Figure $6 \mathrm{a}$ and b). When normalized by the oxide surface area, the $\beta-\mathrm{H}_{2} \mid \mathrm{IO}_{3}$ demonstrates a large OER activity with an overpotential as low as $\sim 345 \mathrm{mV}$ at a current density of $10 \mathrm{~mA} / \mathrm{cm}^{2}{ }_{\text {oxide }}$ in $1.0 \mathrm{M}$ $\mathrm{H}_{2} \mathrm{SO}_{4}$ (see BET results in Table S3). These metrics outperform the ones measured for micron- (this work, Figure 6b) and nano-sized $\mathrm{IrO}_{2}{ }^{15}$ as well as for $\mathrm{La}_{2} \mathrm{LilrO}_{6}{ }^{35}$ or $\mathrm{Ba}_{2} \mathrm{PrIrO}_{6}{ }^{48}$ perovskites and nearly approach the initial activity of today's "stellar" $\mid \mathrm{IO}_{x} / \mathrm{SrIrO}_{3}$ catalyst. This is well in line with previous attributions of high activity to surface Iridium hydroxide species. ${ }^{26,49}$ We should however note that in its powder form, $\mathrm{IrO} / \mathrm{Sr} / \mathrm{HO}_{3}$ catalyst quickly deactivates and finally $\beta-\mathrm{H}_{2} \mid \mathrm{IO}_{3}$ which activity remains relatively stable upon cycling, is found to possess a slightly better OER activity after 300 cycles (Figure $6 \mathrm{~b})$. Moreover, when normalized by the mass of iridium, $\beta$ $\mathrm{H}_{2} \mathrm{IrO}_{3}$ shows better OER performances than $\mathrm{IrO} / \mathrm{SrIrO}$, making this phase very promising as OER catalyst in acidic conditions.

To assess the electrochemical stability of the $\beta-\mathrm{H}_{2} \mid \mathrm{rO}_{3}$ catalyst, ICP-OES measurements were performed over $50 \mathrm{~h}$ at a constant potential of $1.55 \mathrm{~V}$ Vs RHE and the results are compared with $\mathrm{IrO}_{\mathrm{x}} / \mathrm{SrIrO}_{3}$ (Figure 6c). Interestingly, the dissolution rate is found drastically reduced for $\beta-\mathrm{H}_{2} \mid \mathrm{IO}_{3}$ when compared to $\mathrm{IrO}_{\mathrm{x}} / \mathrm{SrIrO}_{3}$. Indeed, less than $0.2 \% \mathrm{Ir}$ was found dissolved after 50 hours, while $\approx 0.45 \%$ Ir were detected in solution for $\mathrm{IrO}_{\mathrm{x}} / \mathrm{SrlrO}_{3}$. This relative stability is further illustrated by the retained electrochemical signature for the potentials below the OER in which three reversible redox peaks at $0.9 \mathrm{~V}, 1.25 \mathrm{~V}$ and $1.35 \mathrm{~V}$ vs. RHE corresponding to the bulk oxidation/deprotonation previously discussed are observed (Figure 6d and Figure S7). Such observation indicates that the bulk retains its proton exchange properties and that no significant increase of the active surface area or obvious modification of the surface chemistry occurs upon cycling (Figure $6 \mathrm{~d}$ ). This is in direct contrast with previous reports correlating the changes in the capacitive signature of transition metal oxides to surface modifications. ${ }^{50}$ Furthermore, the amorphous layer formed on the surface of the particles during the initial protonation (Figure 2c) shows little to no thickness increase during OER, even after $300 \mathrm{CV}$ cycles as evidenced by HAADF-STEM images of ex situ samples (Figure S8). Overall, this low dissolution rate and limited surface reconstruction is quite surprising considering the high surface area which, intuitively, should show opposite trends. On the other hand, $\mathrm{SrIrO}_{3}$ initially displays several sharp redox peaks below $1.5 \mathrm{~V}$, presumably related to a dissolution/re-precipitation process, which quickly disappear after a few cycles to leave only a capacitive current corresponding to the signature of the $\operatorname{IrO}_{x}$ shell (Figure S7).

Altogether, these results highlight that during the OER the bulk of the protonated iridium oxide catalyst is involved into a reversible charge balance process. Indeed, upon anodic polarization corresponding to the OER conditions, the protonated iridium oxide is oxidized (deprotonated), as we
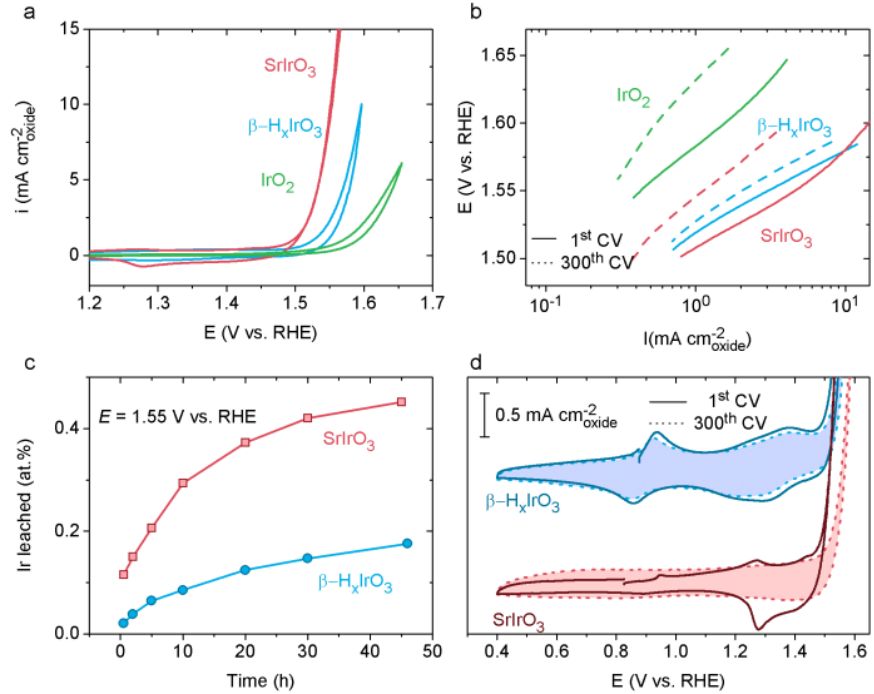

Figure 6 Comparison of the OER activities and stabilities in acid. (a) Cyclic voltammograms of $\mathrm{IrO}_{2}, \beta-\mathrm{H}_{2} \mid \mathrm{IO}_{3}$ and $\mathrm{SrIrO}_{3}$ in $1 \mathrm{M} \mathrm{H}_{2} \mathrm{SO}_{4}$ solution using a rotating disk electrode. (b) Tafel plots of various electrocatalysts in acid media. (c) Ir dissolution upon time normalized by the oxide surface area as measured by ICP-OES for $\beta-\mathrm{H}_{2} \mid \mathrm{IO}_{3}$, $\mathrm{SrIOO}_{3}, \mathrm{IrO}_{2}$. (d) Enlarged CV curves depicting the evolution of capacitance regions for $\beta-\mathrm{H}_{2} \mid \mathrm{rO}_{3}$ (blue) and $\mathrm{SrlrO}_{3}$ from this study (red) cycled in $1.0 \mathrm{M} \mathrm{H}_{2} \mathrm{SO}_{4}$ acidic solution for 300 cycles ( 20 hours) at a scan rate of $10 \mathrm{mV} / \mathrm{s}\left(1^{\text {st }}\right.$ cycle in solid line and $300^{\text {th }}$ cycle in dash line).

uncovered by bulk sensitive operando XAS (Figure $5 \mathrm{~d}$ ). The deintercalation of protons from the bulk of the particles raises the redox potential of the catalyst above the one of water, thus creating a driving force for the surface to react with water. As we previously described, this 3D iridium oxide possesses an electronic structure in which non-bonding $\mathrm{O} 2 p$ levels are redox active and account for the charge balance upon delithiation for $y \leq 1.5$ in $\beta-A_{y} \mid r O_{3}{ }^{43}$ Hence, upon oxidation electrophilic oxygen are created and serve as active sites for water oxidation, in agreement with previous results. ${ }^{25,37,51}$ Second, upon reactivity with water, proton intercalate from the solution into the bulk of $\beta-\mathrm{H}_{\mathrm{y}} \mathrm{IrO} \mathrm{O}_{3}$ (Figure $5 b)$; this charge balance mechanism helps stabilizing the catalyst and reduces the dissolution of iridium when compared to other iridium based oxides.

While we uncovered this mechanism for the $\beta-\mathrm{H}_{2} \mid \mathrm{IO}_{3}$ protonated catalyst, it is worth mentioning that this result is in line with observations previously made for state-of-the-art protonated $\mathrm{IrO}_{\mathrm{x}}$ catalysts or for more complex oxides such as perovskites. Indeed, Minguzzi et al. previously observed by operando XAS for $\mathrm{IrO}_{\mathrm{x}}$ a first oxidation event up to $\mathrm{Ir}^{5+}$ prior to reaching the OER potential, followed by a reduction of iridium when reaching a potential at which oxygen is generated in acidic environment. ${ }^{52}$ Similar reduction of the iridium oxidation state below 4+ was also observed after the OER for $\mathrm{La}_{2} \mathrm{LilOO}_{6}$, this reduction being accompanied by the formation of IrO $_{x}$-type particles. ${ }^{35}$ Nevertheless, observations of this process was so far limited to surfaces while we found for $\beta$ $\mathrm{H}_{2} \mid \mathrm{IO}_{3}$ that when extended to the bulk of the particle it allows for stabilizing the catalyst in these strongly acidic conditions. Finally, this behavior contrasts with the one observed for the thermally prepared $\mathrm{IrO}_{2}$ catalyst which is found more stable but less active than its protonated $\mathrm{IrO}_{\mathrm{x}}$ counterpart. ${ }^{53}$

Therefore, designing compounds with the ability to reversibly exchange protons can play a pivotal role in the development of active and stable OER catalysts in acid media. Nevertheless, the redox peaks observed for the initial delithiation of $\beta-\mathrm{Li}_{2} \mid \mathrm{IO}_{3}$ show greater intensities than those 
measured for the protonated $\beta-\mathrm{H}_{2} \mathrm{IrO}_{3}$ phase which correspond to the deprotonation of $10 \%$ of the catalyst (Figure 3a). This observation suggests that while sufficient to stabilize the mechanism and avoid iridium dissolution, the proton diffusion in this 3D oxide framework is rather slow when compared to the lithium diffusion. This is confirmed by ${ }^{7} \mathrm{Li}$ and ${ }^{1} \mathrm{H}$ NMR spectroscopy which shows fast exchange between the two Li sites while the chemical exchange between some protons sites were found extremely slow (Figure S2 and S9). With this in mind, strategies can be envisioned in order to design oxides with an enhanced proton affinity for OER active surfaces. The first one is the partial substitution of iridium (or ruthenium) by less electronegative $3 d$ transition metals to create two populations of oxygen: 1) the oxygen ions covalently bonded to iridium and serving as OER active sites and 2 ) the oxygen ions more ionically bonded to metal cations such as titanium or vanadium and thus more basic, i.e. prone to protonation. Bearing in mind that, following the proposed mechanism, two protons must be exchanged per Ir in order to preserve the charge neutrality of the oxide catalyst upon chemical OER, bulk diffusion such as the one found for the $\beta$ $\mathrm{H}_{2} \mathrm{IrO}_{3}$ phase should be privileged compared to surface protonation which would certainly limit both the activity and the stability of the catalyst. Hence, the wise selection of transition metal cations will not be sufficient and it must be coupled with the use of adapted crystallographic structures in order to stabilize this mechanism.

\section{Conclusions}

In summary, we have confirmed by the isolation of the $\beta$ $\mathrm{IrO}_{3}$ intermediate that the formation of high valence iridium oxide intermediate is responsible for the high activity of iridium-based catalysts, as well as their limited stability. Coupling XAS and XPS spectroscopic tools, we observed that this activity/stability relationship is correlated with the formation of electrophilic " $\mathrm{O}$ " " oxygen species which chemically react with water to generate gaseous oxygen, while being prone to dissolution, in agreement with previous discussions. ${ }^{35,25,36,37}$ Coupling these measurements with structural refinement, we demonstrated that upon chemical reactivity with water, protons are inserted into the structure of this intermediate to form a new protonated phase following the overall reaction $\mathrm{IrO}_{3}+\mathrm{H}_{2} \mathrm{O} \rightarrow \mathrm{H}_{2} \mid \mathrm{IO}_{3}+1 / 2 \mathrm{O}_{2}$. We could further demonstrate that the bulk of this protonated phase is then redox active upon OER and that protons are continuously exchanged with the solution, thus regenerating the catalyst and keeping its chemical integrity. Furthermore, this ability for the catalyst to accept protons by bulk insertion limits the dissolution of iridium cations which is usually encountered at high potential for iridium oxide OER catalysts. Finally, we believe that this discovery opens up new avenues for designing better and more stable OER catalysts for acidic environment by controlling 1 ) the protonation state of oxygen through a fine tuning of the iono-covalency of the metal-oxygen bond and 2) the bulk proton diffusivity with a wise choice of crystallographic structures.

\section{Conflicts of interest}

There are no conflicts to declare.

\section{Acknowledgements}

The authors would like to extend their appreciation to Manel Ben Osman for the BET measurements and to Christel Laberty for her cooperation. The authors would like to express their gratitude to Camille Douard, Fanch Guillou and Thierry Brousse from the Institut des matériaux Jean Rouxel in Nantes, France, for lending us the operando XAS cell used for this study. The authors would also like to thank Matthieu Courty from the Laboratoire de réactivité et chimie des solides in Amiens, France, for carrying out the TGA-MS measurements. This work is based on experiments performed on the D20 neutron diffractometer at the Institut Laue Langevin, Grenoble, France and on the ROCK beamline at Soleil synchrotron, France. J.-M.T. acknowledges funding from the European Research Council (ERC) (FP/2014)/ERC Grant-Project 670116-ARPEMA. The authors thank Stéphanie Belin for her assistance during beamtime at the ROCK beamline (financed by the French National Research Agency (ANR) as a part of the "Investissements d'Avenir" program, reference: ANR-10EQPX-45; Rapid Access \#20180904) and James Ablett and JeanPascal Rueff for their assistance during the HAXPES experiments on the GALAXIES beamline, SOLEIL Synchrotron, France. A.G. acknowledges financial support from the ANR MIDWAY (Project ID: ANR-17-CE05-0008).

\section{Notes and references}

1 N. S. Lewis and D. G. Nocera, Proc. Natl. Acad. Sci., 2006, 103, 15729-15735.

2 V. R. Stamenkovic, D. Strmcnik, P. P. Lopes and N. M. Markovic, Nat. Mater., 2017, 16, 57-69.

3 W. T. Hong, M. Risch, K. A. Stoerzinger, A. Grimaud, J. Suntivich and Y. Shao-Horn, Energy Environ. Sci., 2015, 8, 14041427.

4 J. H. Montoya, L. C. Seitz, P. Chakthranont, A. Vojvodic, T. F. Jaramillo and J. K. Nørskov, Nat. Mater., 2017, 16, 70-81.

5 M. W. Kanan and D. G. Nocera, Science, 2008, 321, 10721075.

6 A. Grimaud, K. J. May, C. E. Carlton, Y.-L. Lee, M. Risch, W. T. Hong, J. Zhou and Y. Shao-Horn, Nat. Commun., 2013, 4, 2439.

7 J. Suntivich, K. J. May, H. A. Gasteiger, J. B. Goodenough and Y. Shao-Horn, Science, 2011, 334, 1383-1385.

8 J. T. Mefford, X. Rong, A. M. Abakumov, W. G. Hardin, S. Dai, A. M. Kolpak, K. P. Johnston and K. J. Stevenson, Nat. Commun., 2016, 7, 11053.

9 E. Fabbri, A. Habereder, K. Waltar, R. Kötz and T. J. Schmidt, Catal. Sci. Technol., 2014, 4, 3800-3821.

10 E. Fabbri, M. Nachtegaal, T. Binninger, X. Cheng, B.-J. Kim, J. Durst, F. Bozza, T. Graule, R. Schäublin, L. Wiles, M. Pertoso, N. Danilovic, K. E. Ayers and T. J. Schmidt, Nat. Mater., 2017, 16, 925-931.

11 S. Cherevko, A. R. Zeradjanin, A. A. Topalov, N. Kulyk, I. Katsounaros and K. J. J. Mayrhofer, ChemCatChem, 2014, 6, 2219-2223.

12 S. Geiger, O. Kasian, M. Ledendecker, E. Pizzutilo, A. M. Mingers, W. T. Fu, O. Diaz-Morales, Z. Li, T. Oellers, L. Fruchter, 
A. Ludwig, K. J. J. Mayrhofer, M. T. M. Koper and S. Cherevko, Nature Catalysis, 2018, 1, 508-515.

13 M. Pourbaix, Atlas of Electrochemical Equilibria in Aqueous Solutions, National Association of Corrosion Engineers, 1974.

14 J. W. D. Ng, M. García-Melchor, M. Bajdich, P. Chakthranont, C. Kirk, A. Vojvodic and T. F. Jaramillo, Nat. Energy, 2016, 1, 16053.

15 Y. Lee, J. Suntivich, K. J. May, E. E. Perry and Y. Shao-Horn, J. Phys. Chem. Lett., 2012, 3, 399-404.

16 P. Lettenmeier, L. Wang, U. Golla-Schindler, P. Gazdzicki, N. A. Cañas, M. Handl, R. Hiesgen, S. S. Hosseiny, A. S. Gago and K. A. Friedrich, Angew. Chem., 2016, 128, 752-756.

17 T. Reier, H. N. Nong, D. Teschner, R. Schlögl and P. Strasser, Adv. Energy Mater., 2017, 7, 1601275.

18 R. R. Rao, M. J. Kolb, N. B. Halck, A. F. Pedersen, A. Mehta, H. You, K. A. Stoerzinger, Z. Feng, H. A. Hansen, H. Zhou, L. Giordano, J. Rossmeisl, T. Vegge, I. Chorkendorff, I. E. L. Stephens and Y. Shao-Horn, Energy Environ. Sci., 2017, 10, 26262637.

19 C. Spöri, J. T. H. Kwan, A. Bonakdarpour, D. P. Wilkinson and P. Strasser, Angew. Chem., Int. Ed. Engl., 2017, 56, 5994-6021.

20 P. Jovanovič, N. Hodnik, F. Ruiz-Zepeda, I. Arčon, B. Jozinović, M. Zorko, M. Bele, M. Šala, V. S. Šelih, S. Hočevar and M. Gaberšček, Journal of the American Chemical Society, 2017, 139, 12837-12846.

21 A. Grimaud, A. Demortière, M. Saubanère, W. Dachraoui, M. Duchamp, M.-L. Doublet and J.-M. Tarascon, Nat. Energy, 2016, 2, 16189.

22 T. Li, O. Kasian, S. Cherevko, S. Zhang, S. Geiger, C. Scheu, P. Felfer, D. Raabe, B. Gault and K. J. J. Mayrhofer, Nat. Catalysis, 2018, 1, 300-305.

23 O. Diaz-Morales, F. Calle-Vallejo, C. de Munck and M. T. M. Koper, Chem. Sci., 2013, 4, 2334.

$24 \mathrm{M}$. Wohlfahrt-Mehrens and J. Heitbaum, J. Electroanal. Chem. Interfacial Electrochem., 1987, 237, 251-260.

25 V. Pfeifer, T. E. Jones, J. J. Velasco Vélez, R. Arrigo, S. Piccinin, M. Hävecker, A. Knop-Gericke and R. Schlögl, Chem. Sci., 2017, 8 2143-2149.

26 D. F. Abbott, D. Lebedev, K. Waltar, M. Povia, M. Nachtegaal, E. Fabbri, C. Copéret and T. J. Schmidt, Chem. Mater., 2016, 28 6591-6604.

27 A. Minguzzi, C. Locatelli, O. Lugaresi, E. Achilli, G. Cappelletti, M. Scavini, M. Coduri, P. Masala, B. Sacchi, A. Vertova, P. Ghigna and S. Rondinini, ACS Catal., 2015, 5, 5104-5115.

28 D. Weber, L. M. Schoop, D. Wurmbrand, S. Laha, F. Podjaski, V. Duppel, K. Müller, U. Starke and B. V. Lotsch, Journal of Materials Chemistry A, 2018, 6, 21558-21566.

29 K. Klyukin, A. Zagalskaya and V. Alexandrov, The Journal of Physical Chemistry C, 2018, 122, 29350-29358.

30 C. Costentin and D. G. Nocera, Proc. Natl. Acad. Sci., 2017 114, 13380-13384.

31 T. Reier, Z. Pawolek, S. Cherevko, M. Bruns, T. Jones, D. Teschner, S. Selve, A. Bergmann, H. N. Nong, R. Schlögl, K. J. J. Mayrhofer and P. Strasser, J. Am. Chem. Soc., 2015, 137, 1303113040.

32 H. N. Nong, H.-S. Oh, T. Reier, E. Willinger, M.-G. Willinger, V. Petkov, D. Teschner and P. Strasser, Angew. Chem., Int. Ed. Engl., 2015, 54, 2975-2979.

33 H. G. Sanchez Casalongue, M. L. Ng, S. Kaya, D. Friebel, H. Ogasawara and A. Nilsson, Angew. Chem., 2014, 126, 72977300.

34 L. C. Seitz, C. F. Dickens, K. Nishio, Y. Hikita, J. Montoya, A. Doyle, C. Kirk, A. Vojvodic, H. Y. Hwang and J. K. Norskov, Science, 2016, 353, 1011-1014.

35 A. Grimaud, A. Demortiere, M. Saubanère, W. Dachraoui, M. Duchamp, M.-L. Doublet and J.-M. Tarascon, Narue Energy, 2, 16189.

36 O. Kasian, J.-P. Grote, S. Geiger, S. Cherevko and K. J. J. Mayrhofer, Angew. Chem., Int. Ed. Engl., 2018, 57, 2488-2491.

37 V. A. Saveleva, L. Wang, D. Teschner, T. Jones, A. S. Gago, K. A. Friedrich, S. Zafeiratos, R. Schlögl and E. R. Savinova, J. Phys. Chem. Lett., 2018, 9, 3154-3160.
38 E. Willinger, C. Massué, R. Schlögl and M. G. Willinger, J. Am. Chem. Soc., 2017, 139, 12093-12101.

39 V. Pfeifer, T. E. Jones, S. Wrabetz, C. Massué, J. J. Velasco Vélez, R. Arrigo, M. Scherzer, S. Piccinin, M. Hävecker, A. KnopGericke and R. Schlögl, Chemical Science, 2016, 7, 6791-6795.

40 I. C. Man, H.-Y. Su, F. Calle-Vallejo, H. A. Hansen, J. I. Martínez, N. G. Inoglu, J. Kitchin, T. F. Jaramillo, J. K. Nørskov and J. Rossmeisl, Chem CatChem, 2011, 3, 1159-1165.

41 R. Kötz, H. Neff and S. Stucki, J. Electrochem. Soc., 1984, 131, 72-77.

42 R. Zhang, N. Dubouis, M. Ben Osman, W. Yin, M. T. Sougrati, D. A. D. Corte, D. Giaume and A. Grimaud, Angew. Chem., Int Ed. Engl., 2019, 58, 4571-4575.

43 P. E. Pearce, A. J. Perez, G. Rousse, M. Saubanère, D. Batuk D. Foix, E. McCalla, A. M. Abakumov, G. Van Tendeloo, M.-L. Doublet and J.-M. Tarascon, Nat. Mater., 2017, 16, 580-586.

44 M. G. Mavros, T. Tsuchimochi, T. Kowalczyk, A. Mclsaac, L.-P. Wang and T. V. Voorhis, Inorg. Chem., 2014, 53, 6386-6397.

45 S. J. Freakley, J. Ruiz-Esquius and D. J. Morgan, Surface and Interface Analysis, 2017, 49, 794-799.

46 A. Iadecola, A. Perea, L. Aldon, G. Aquilanti and L. Stievano, J. Phys. D: Appl. Phys., 2017, 50, 144004.

47 G. Assat, A. ladecola, C. Delacourt, R. Dedryvère and J.-M. Tarascon, Chem. Mater., 2017, 29, 9714-9724.

48 O. Diaz-Morales, S. Raaijman, R. Kortlever, P. J. Kooyman, T. Wezendonk, J. Gascon, W. T. Fu and M. T. M. Koper, Nat. Commun., 2016, 7, 12363.

49 X. Tan, J. Shen, N. Semagina and M. Secanell, Journal of Catalysis, 2019, 371, 57-70.

50 A. Grimaud, O. Diaz-Morales, B. Han, W. T. Hong, Y.-L. Lee, L. Giordano, K. A. Stoerzinger, M. T. M. Koper and Y. Shao-Horn, Nat. Chem., 2017, 9, 457-465.

51 D. N. Mueller, M. L. Machala, H. Bluhm and W. C. Chueh, Nat. Commun., 2015, 6, 6097.

52 A. Minguzzi, O. Lugaresi, E. Achilli, C. Locatelli, A. Vertova, P. Ghigna and S. Rondinini, Chem. Sci., 2014, 5, 3591-3597.

53 S. Geiger, O. Kasian, B. R. Shrestha, A. M. Mingers, K. J. Mayrhofer and S. Cherevko, J. Electrochem. Soc., 2016, 163, F3132-F3138. 


\section{Supplementary Materials for}

\section{Revealing the reactivity of the Iridium trioxide intermediate for the oxygen evolution reaction in acidic media}

Paul E. Pearce, ${ }^{\# 1,2,3}$ Chunzhen Yang, ${ }^{\# 1,3}$ Antonella Iadecola, ${ }^{3}$ Juan Rodriguez-Carvajal, ${ }^{4}$ Gwenaëlle Rousse, ${ }^{1,2,3}$ Rémi Dedryvère, ${ }^{3,5}$ Artem M. Abakumov, ${ }^{6}$ Domitille Giaume,,3 Michael Deschamps, ${ }^{3,8}$ Jean-Marie Tarascon ${ }^{1,2,3,9}$ and Alexis Grimaud*1,3

${ }^{1}$ Chimie du Solide et de l'Energie, UMR 8260, Collège de France, 11 Place Marcelin Berthelot, 75231 Paris Cedex 05, France

${ }^{2}$ Sorbonne Université, 4 place Jussieu, Paris, France

${ }^{3}$ Réseau sur le Stockage Electrochimique de l'Energie (RS2E), CNRS FR 3459, 33 rue Saint Leu, 80039 Amiens Cedex, France

${ }^{4}$ Institut Laue-Langevin, 71 Avenue des Martyrs, CS 20156, 38042, Grenoble, Cedex 9, France

${ }^{5}$ IPREM - UMR 5254 CNRS, Université de Pau et des Pays de l'Adour, Hélioparc, 2 Avenue Pierre Angot, 64053 Pau Cedex 9, France

${ }^{6}$ Skoltech Center for Energy Science and Technology, Skolkovo Institute of Science and Technology, Moscow 121205, Russian Federation

${ }^{7}$ Chimie-Paris Tech, PSL Research University, CNRS Institut de Recherche de Chimie-Paris (IRCP), 75005 Paris, France

${ }^{8}$ CNRS, CEMHTI UPR3079, Universite d'Orleans, 1D avenue de la recherche scientifique, 45071 Orleans Cedex 2, France

${ }^{9}$ ALISTORE-European Research Institute, FR CNRS 3104, 80039 Amiens, France

\# Co-first authors

* Correspondence to: alexis.grimaud@college-de-france.fr 


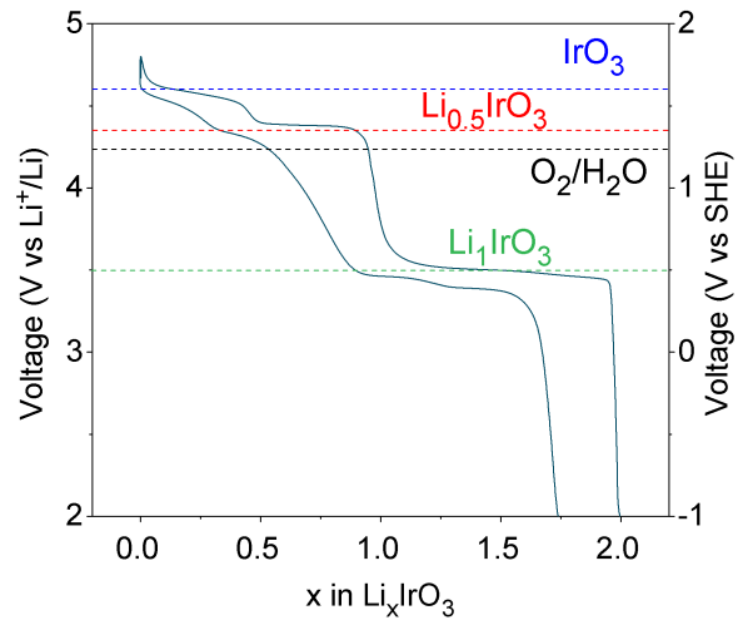

Figure S 1 Galvanostatic charge-discharge profile showing the delithiation potential of $\beta-\mathrm{Li}_{2} \mathrm{IrO} \mathrm{I}_{3}$ in Li-ion battery using LP100 electrolyte. The dashed black line corresponds to the OER potential at $\mathrm{pH} 0, \mathrm{E}=1.23 \mathrm{~V}$ vs. NHE. The blue, red and green dashed lines correspond to the potential for compositions $\mathrm{x}=0,0.5$ and 1 respectively. 


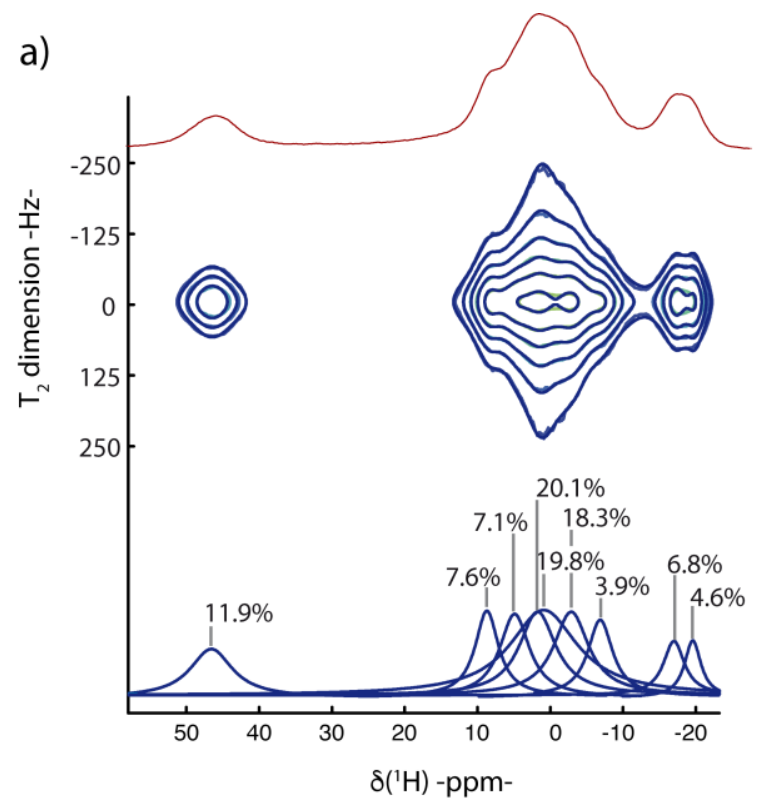

b)

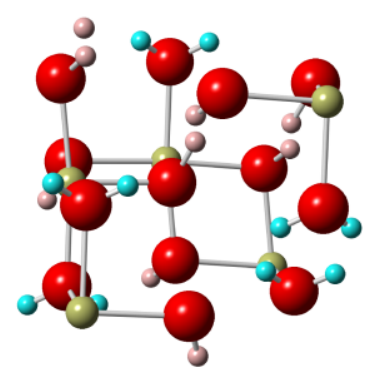

c)

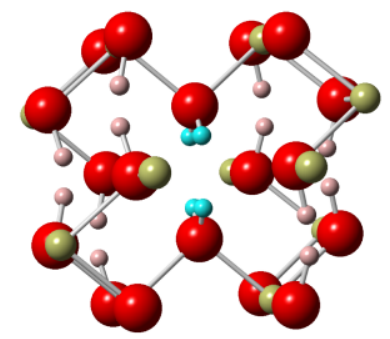

d)

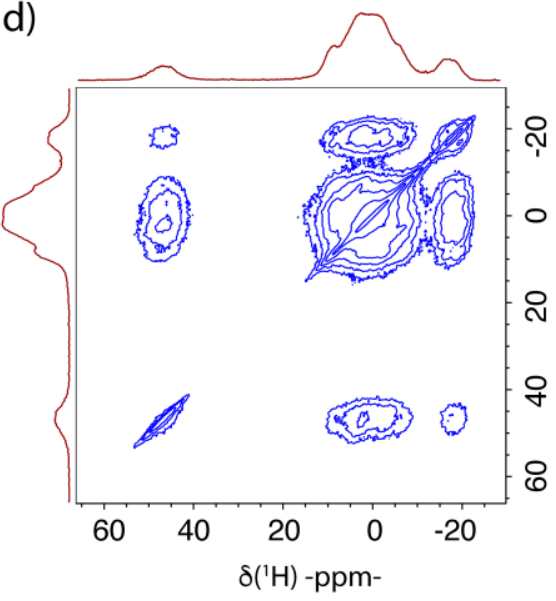

e)
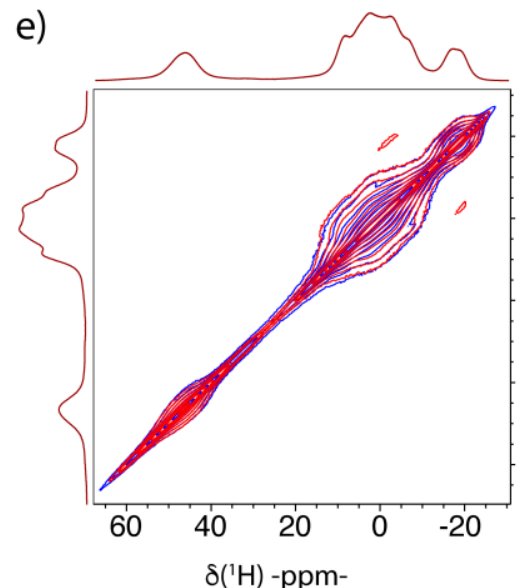

f)

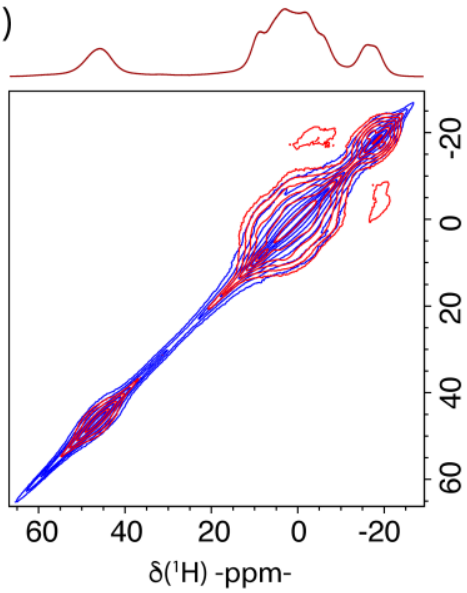

Figure S 2 H NMR. a) 1D 1H MAS-NMR Hahn echo spectrum of $\beta-\mathrm{H}_{2} \mathrm{IrO}_{3}$ recorded at $4.7 \mathrm{~T}$ and a 64 kHz MAS rate, with below the 2D Hahn echo spectrum obtained after the real Fourier transform against the echo time in the indirect dimension and the corresponding fit in blue(obtained with dmfit $^{1}$ ). The 9 detected environments with their respective weights in the 1D spectrum are shown at the bottom, and the $\mathrm{T}_{2}$ 's ranged between 2 and $4 \mathrm{~ms}$, except for the broad peak in the center, which has a $\mathrm{T}_{2}=0.06 \mathrm{~ms}$; b)-c) atomic environments for $\mathrm{H} 1$ (pink) and $\mathrm{H} 2$ (blue), where $\mathrm{H} 1$ sites have a roughly a $50 \%$ occupancy and $\mathrm{H} 2$ sites a $25 \%$ occupancy. The disorder in $\mathrm{H} 1 / \mathrm{H} 2$ occupancies give rise to the multiplicity of sites in the ${ }^{1} \mathrm{H}$ spectrum. D) 2D-RFDR homonuclear correlation spectrum obtained with a $2 \mathrm{~ms}$ dipolar recoupling using a XY-16 RFDR train of rotor synchronized $180^{\circ}$ pulses. All the peaks belong to the same phase. e) and f) EXSY spectra obtained with a mixing time of 1 rotor period (15.6 $\mu$ s) -in blue- compared with a 5 ms mixing time (e) and $50 \mathrm{~ms}$ mixing time (f), both in red. 


\section{Capacity of the redox processes under the OER potential}

The capacity of the processes was determined by integrating the area under the peaks below the OER potential. This was done on a curve obtained at $1 \mathrm{mV} / \mathrm{s}$ scan rate in $1 \mathrm{M} \mathrm{H}_{2} \mathrm{SO}_{4}$ solution in order to neglect the capacitive current. Multiple curves were integrated and the values differ only slightly and are around $25 \mathrm{~mA} . \mathrm{h} / \mathrm{g}$.

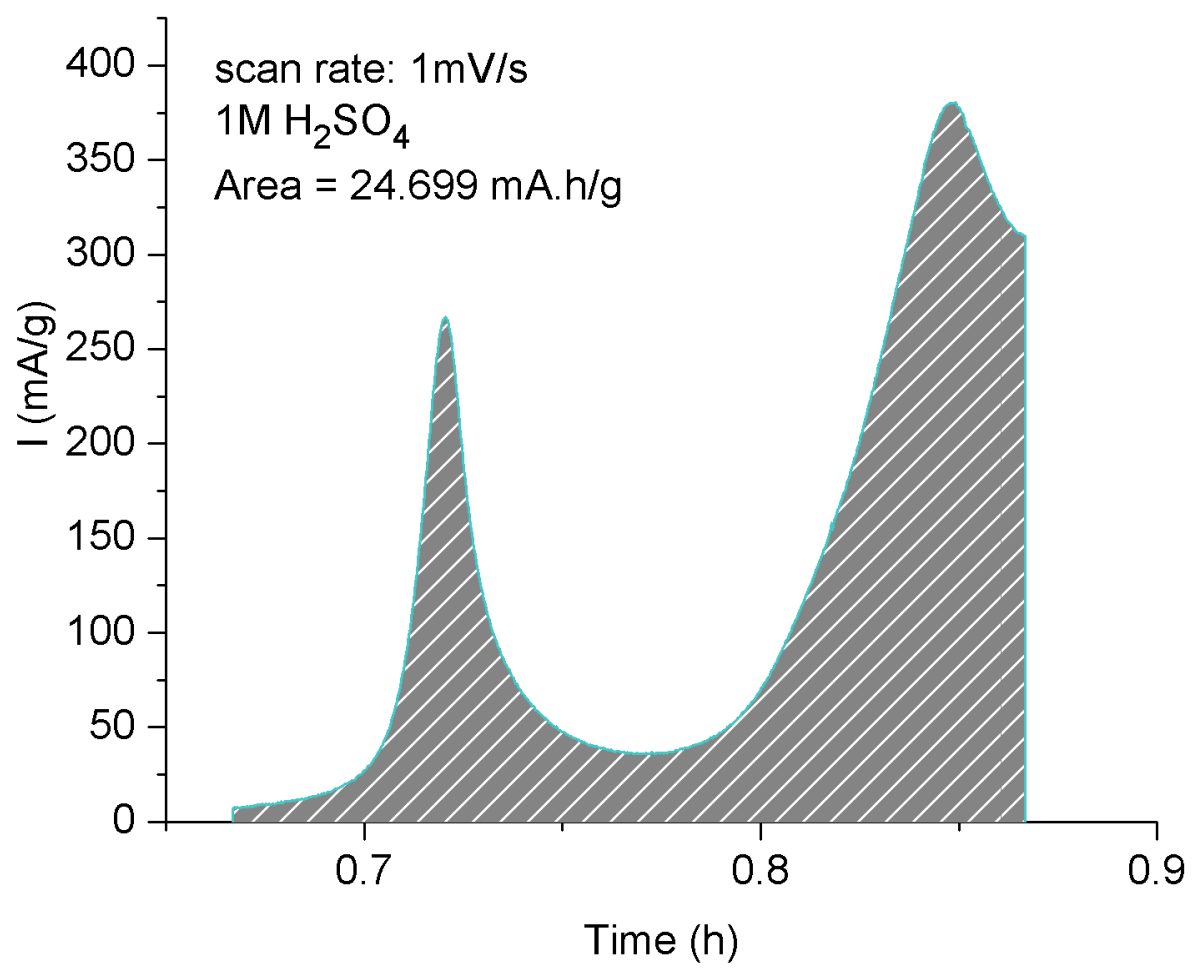

Figure S 3 Cyclic voltammogram of $\beta-\mathrm{H}_{2} \mathrm{IrO}_{3}$ in $1 \mathrm{M} \mathrm{H}_{2} \mathrm{SO}_{4}$ solution at a scan rate of $1 \mathrm{mV} / \mathrm{s}$ showing the integrated area. The data is normalized by the mass of active material.

The theoretical capacity can be obtained by the following relation:

$$
C=\frac{26.8 . \Delta x}{M}
$$

with $\mathrm{C}$ the capacity in A.h/g, $\Delta x$ the number of e- exchanged and $\mathrm{M}$ the molar mass of the compound. The theoretical capacity for $1 \mathrm{H}^{+}$is therefore $110 \mathrm{~mA} \cdot \mathrm{h} / \mathrm{g}$.

The electrochemical processes below the OER potential only account for around $0.1 \mathrm{H}^{+}$extracted. 

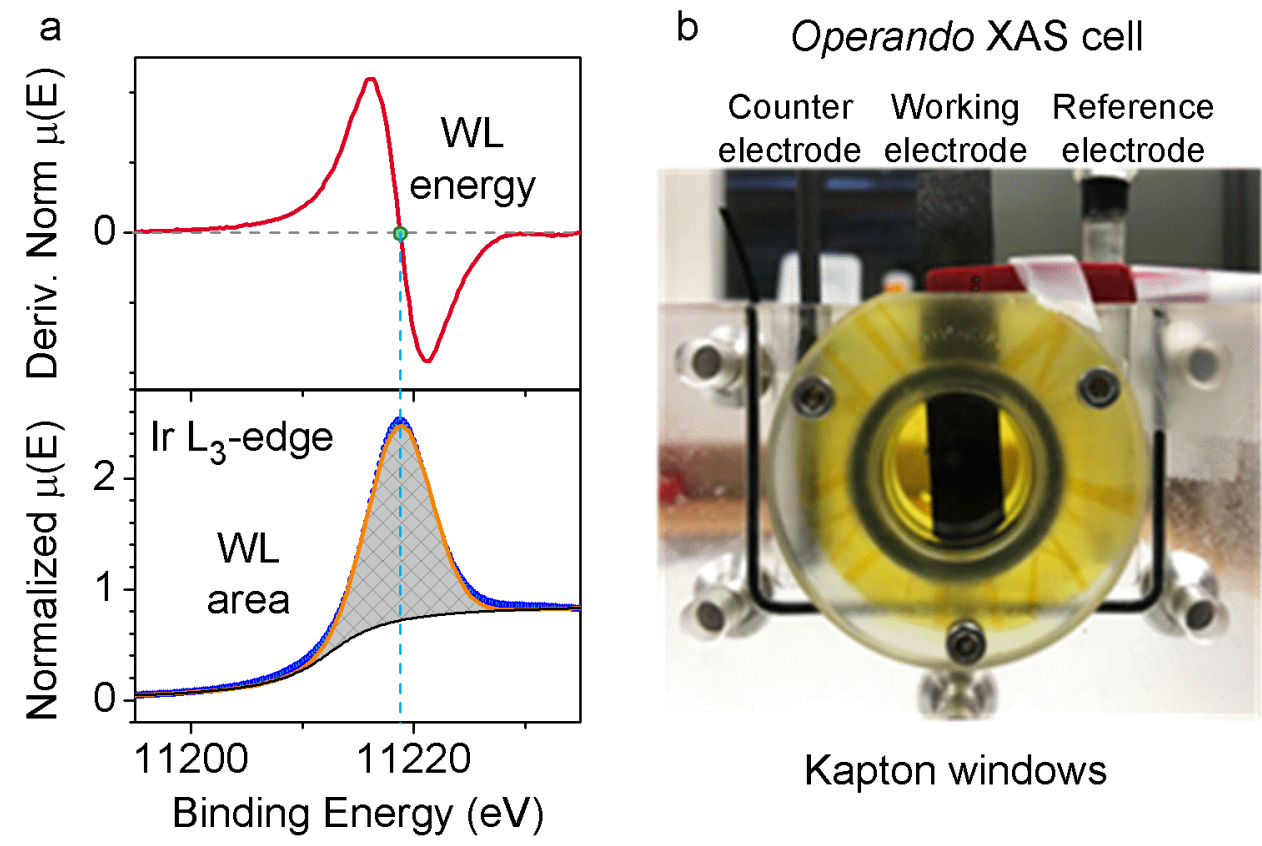

Kapton windows

Figure S 4 Operando XAS data treatment and experimental setup. (a) Derivative of the normalized absorption spectra with the binding energy for which the curve is equal to zero (WL energy) indicated by a green circle. Below is the measured XANES spectra (blue circles), the fitted Gaussian (orange) and the arctan function (back) used to fit the step in absorption. The WL area corresponds to the area between the Gaussian and the arctan functions (hashed). (b) Picture of the home-made electrochemical cell for operating operando XAS experiments, using carbon paper loaded with 5-8 $\mathrm{mg} / \mathrm{cm}^{2}$ geo of $\beta-\mathrm{H}_{2} \mathrm{IrO}_{3}$ catalyst as working electrode, porous graphitic carbon rod as counter electrode, and $\mathrm{Ag} / \mathrm{AgCl}$ ( $\mathrm{KCl}$ sat.) as reference electrode. 
a

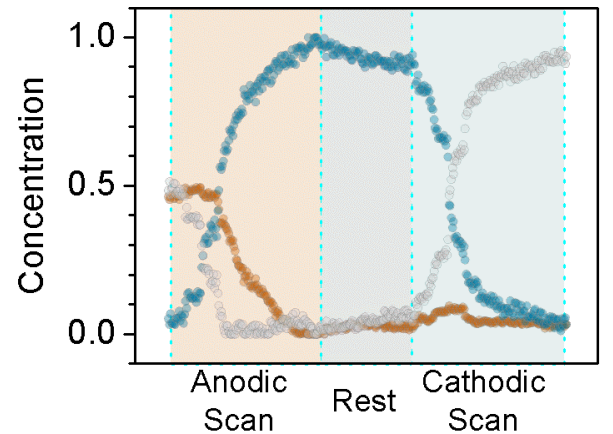

b

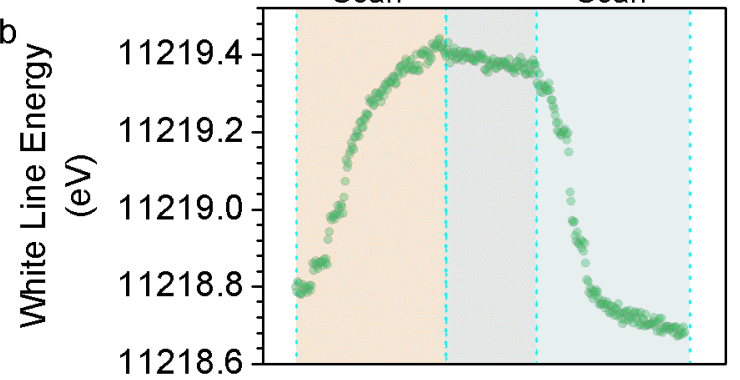

C

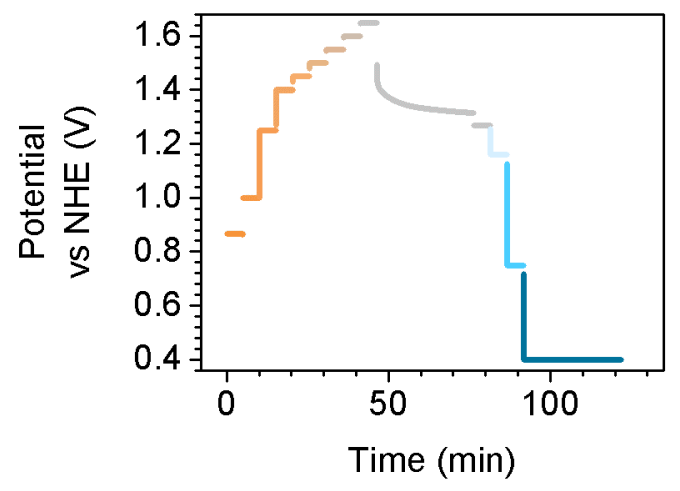

d

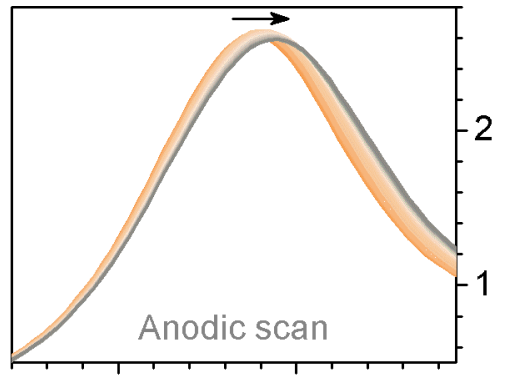

e
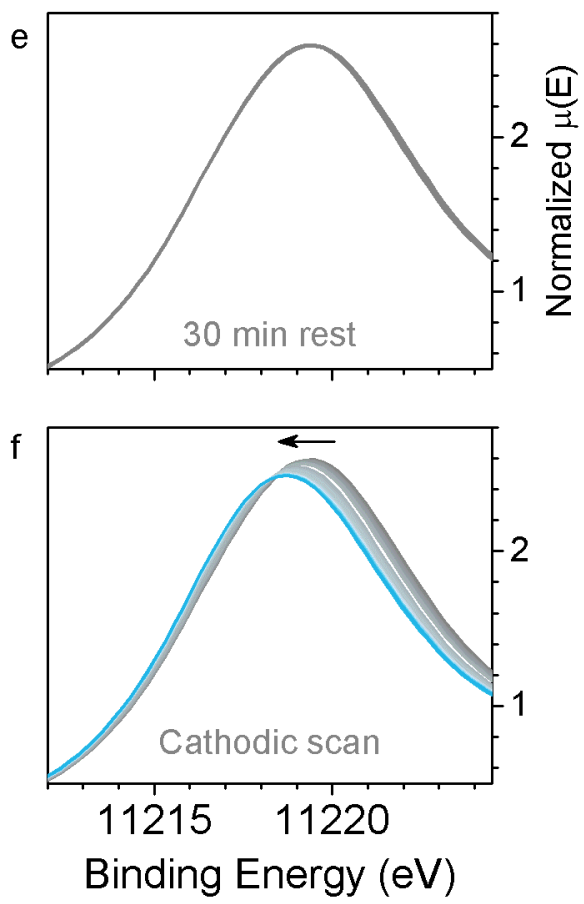

Figure S 5 (a) Concentration profile of components extracted by PCA on the XAS data from the operando experiment for $\beta-\mathrm{Li}_{2} \mathrm{IrO}_{3}$, (b) the white line energy evolution and (c) the corresponding electrochemical curve. (d), (e) and (f) are the normalized XANES spectra for each portion of the experiment. 

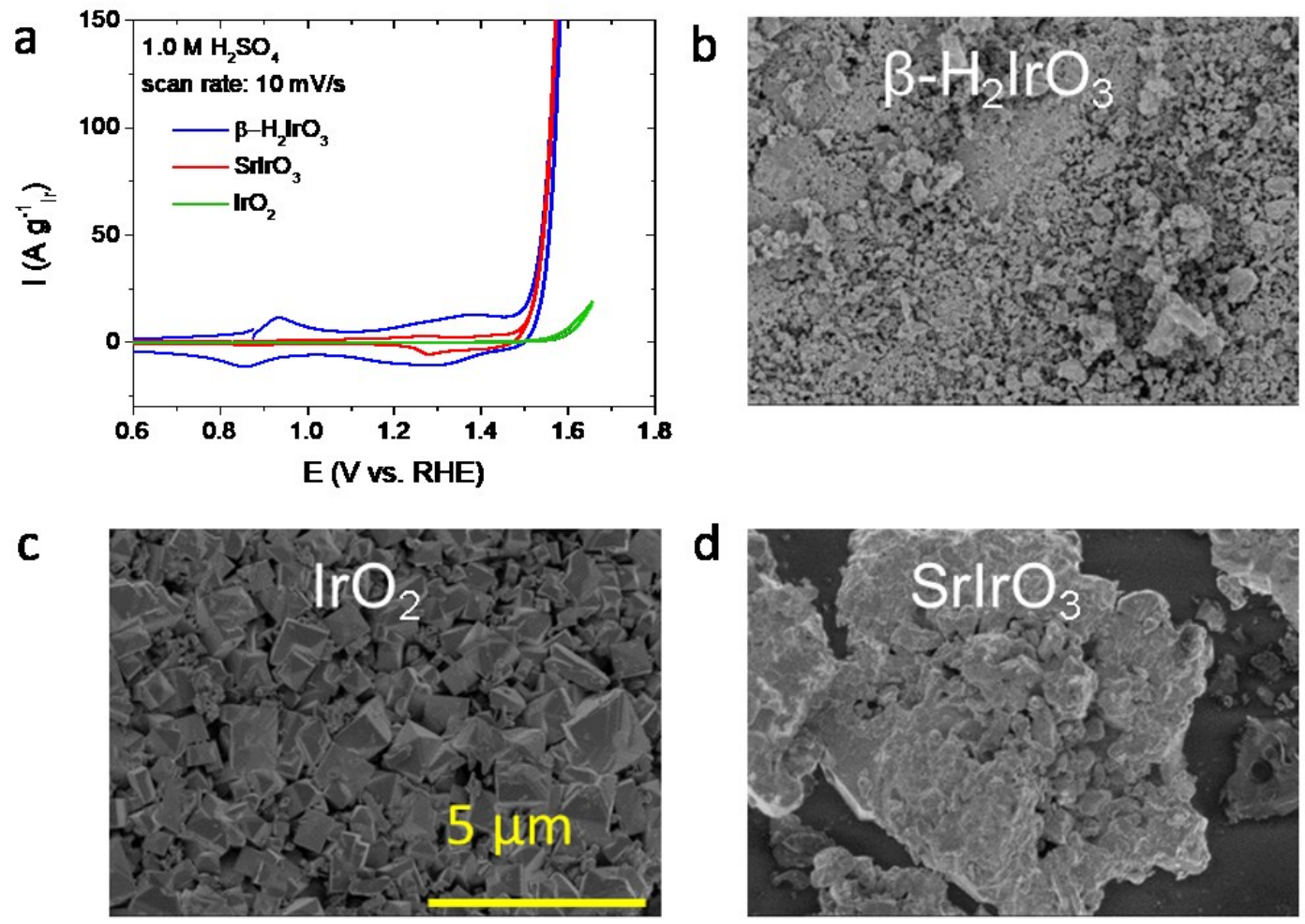

Figure S 6 Comparison of the OER activities normalized by Ir mass. (a) Cyclic voltammograms of $\mathrm{IrO}_{2}, \beta-\mathrm{H}_{\mathrm{x}} \mathrm{IrO}_{3}$ and $\mathrm{SrIrO}_{3}$ in $1 \mathrm{M} \mathrm{H}_{2} \mathrm{SO}_{4}$ solution using a rotating disk electrode. The current is normalized by Ir mass loaded on the electrode. (b-d) SEM micrographs of $\beta-\mathrm{H}_{2} \mathrm{IrO}_{3}, \mathrm{IrO}_{2}$ and $\mathrm{SrIrO}_{3}$ catalysts, respectively. 

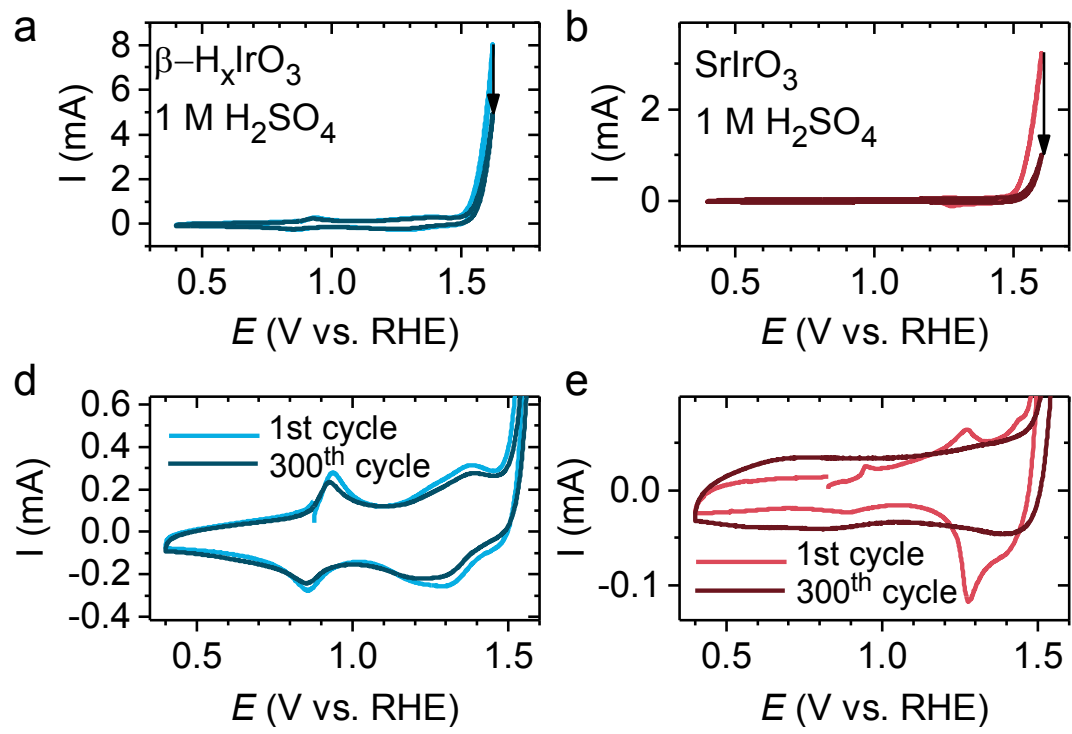

e

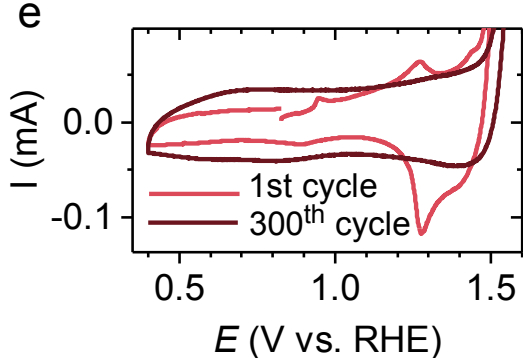

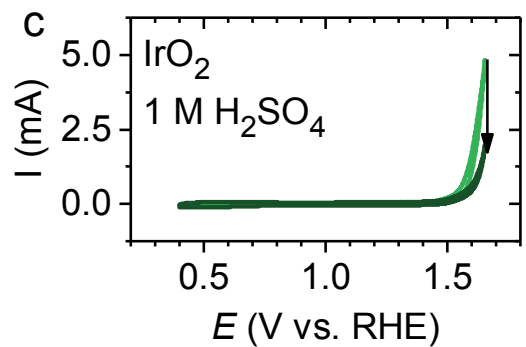

$f$

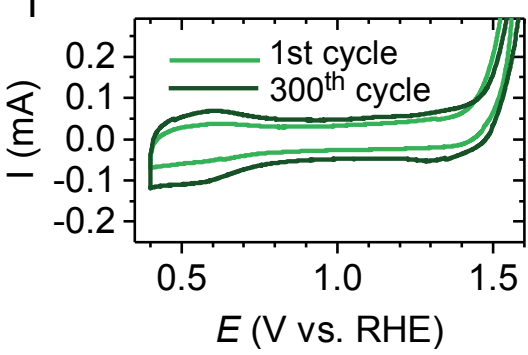

Figure S 7 Comparison of the electrochemical stabilities of (a) $\beta-\mathrm{H}_{\mathrm{x}} \mathrm{IrO}_{3}$, (b) $\mathrm{SrIrO}_{3}$, and (c) $\mathrm{IrO}_{2}$ cycled in $1.0 \mathrm{M} \mathrm{H}_{2} \mathrm{SO}_{4}$ acidic solution for 300 cycles for $\sim 20$ hours at a scan rate of $10 \mathrm{mV} / \mathrm{s}$. Enlarged CV curves depicting the evolution of capacitance regions are shown in (d), (e) and (f), respectively.

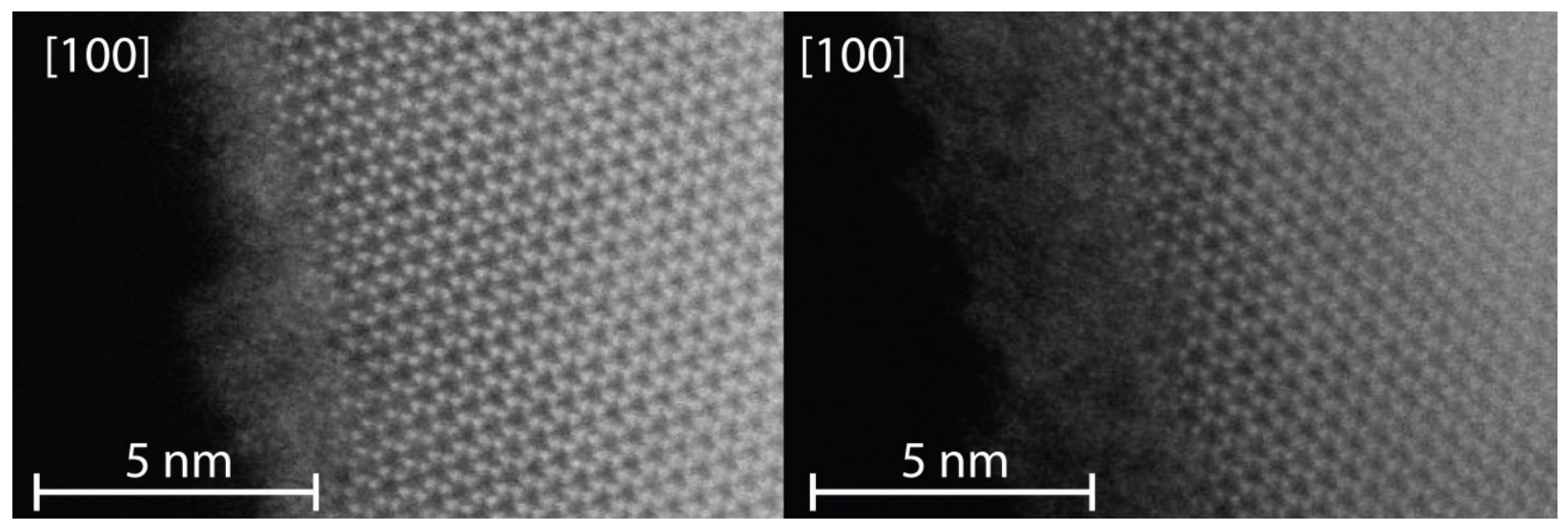

Figure S 8 HAADF-STEM of $\beta-\mathrm{H}_{2} \mathrm{IrO}_{3}$ after 300 cycles to $1.65 \mathrm{~V}$ vs RHE in $1 \mathrm{M} \mathrm{H}_{2} \mathrm{SO}_{4}$ solution. 

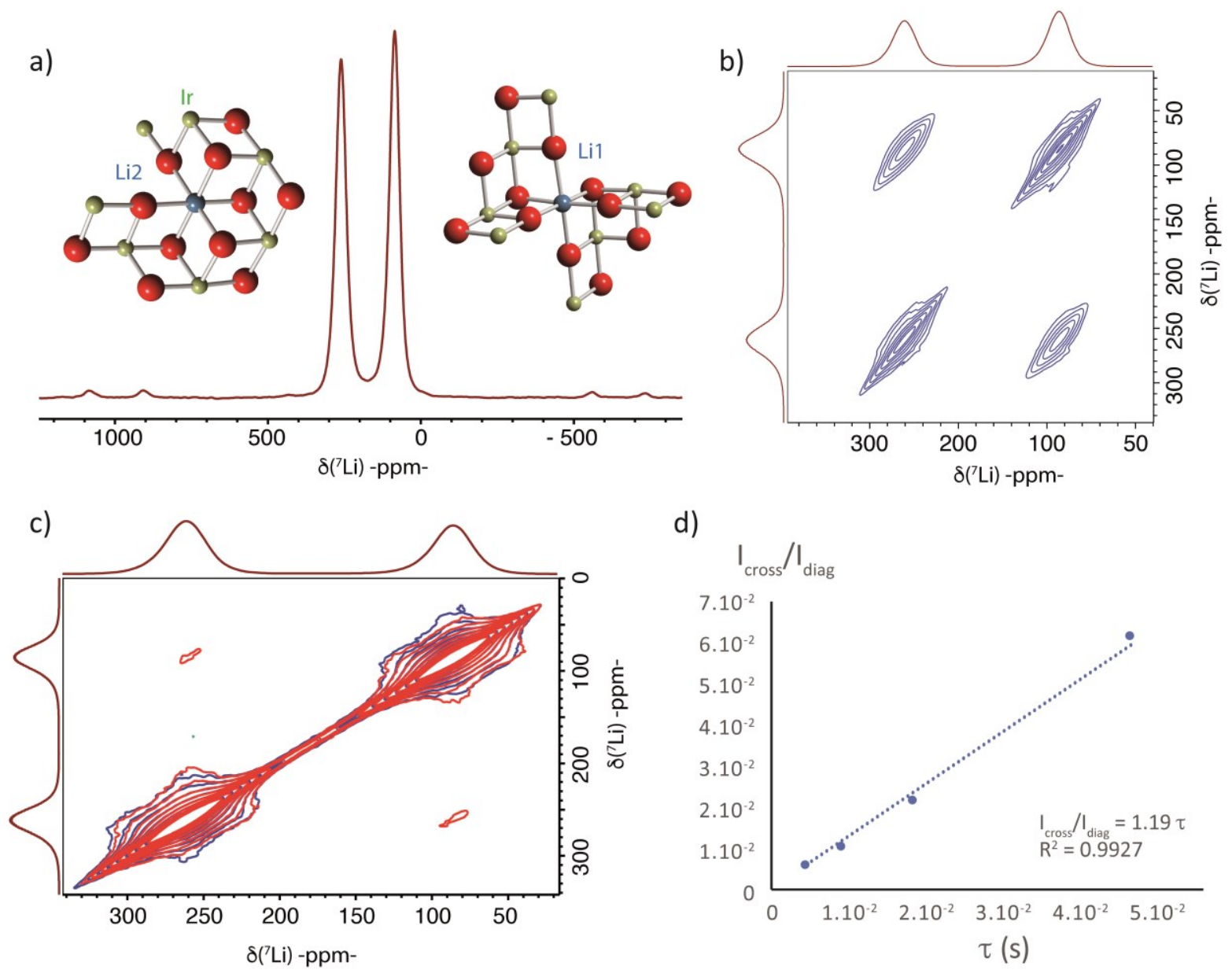

d)

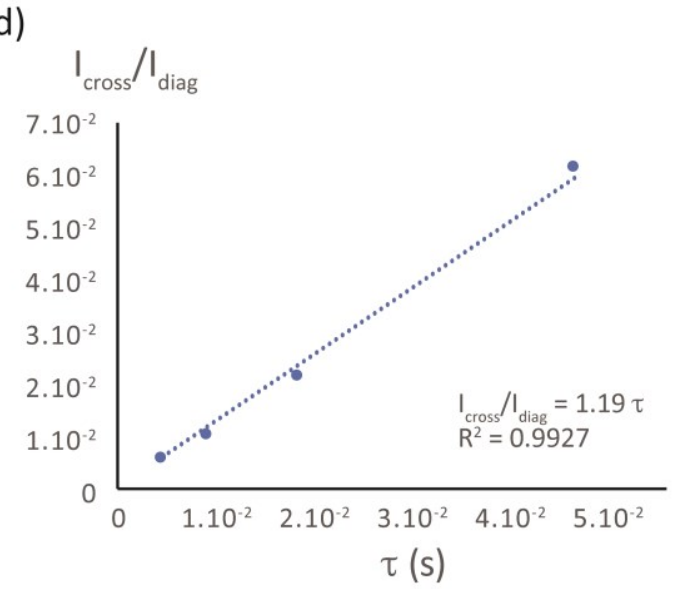

Figure $\mathrm{S} 9 \mathrm{Li}$ NMR. a) ${ }^{7} \mathrm{Li}$ MAS-NMR spectrum of $\beta-\mathrm{Li}_{2} \mathrm{IrO}_{3}$ recorded at $4.7 \mathrm{~T}$ and $64 \mathrm{kHz} \mathrm{MAS}$, featuring the environments of the two lithium sites (blue) in term of oxygen (red) and iridium (green) atoms; b) 2D-RFDR spectrum, using a 4 ms long XY-16 RFDR train of rotor synchronized $180^{\circ}$ pulses for dipolar recoupling, showing the proximity in space of the two detected sites; c) 2DEXSY experiment with the reference spectrum (1 rotor period mixing time) in blue and the 2D EXSY obtained with $5 \mathrm{~ms}$ mixing time in red, displaying weak cross-peaks indicating an exchange between the two sites; d) measuring the ratio between the areas of the cross peak and the diagonal peak leads to the exchange rate constant, measured at $1.19 \mathrm{~s}^{-1}$ at $60-70^{\circ} \mathrm{C}$. 

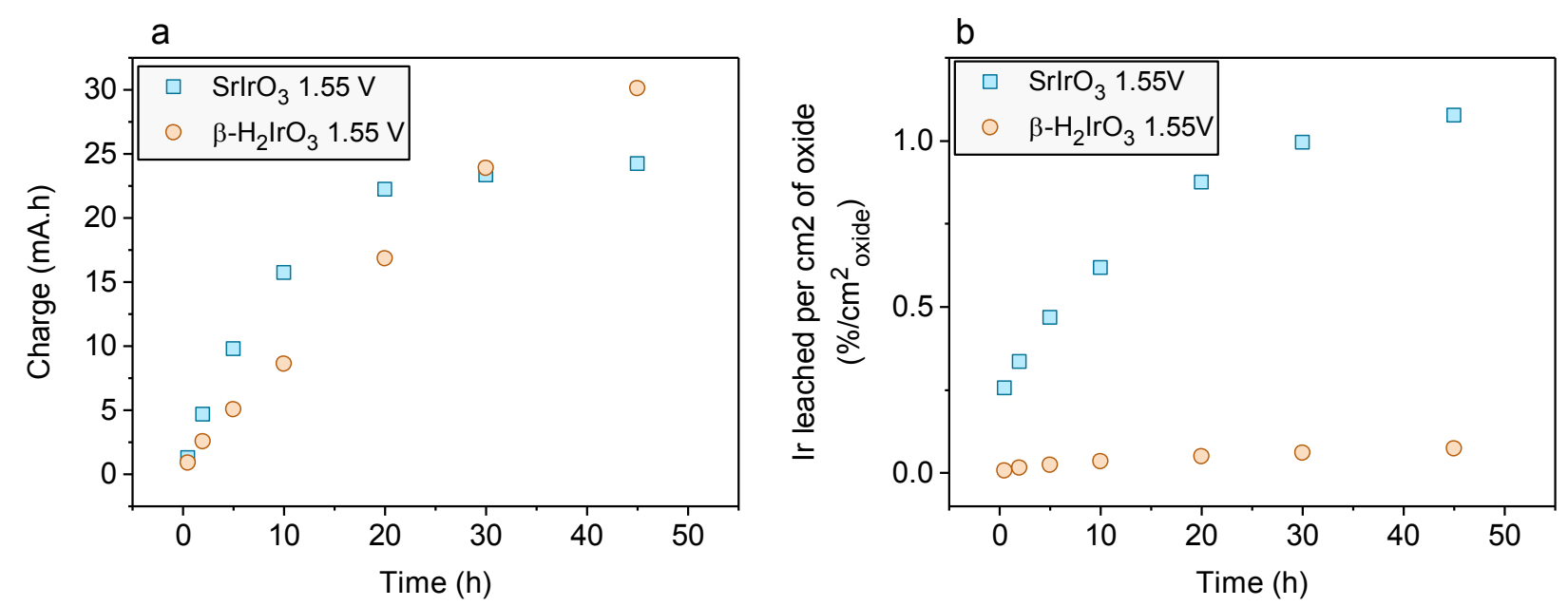

Figure $\mathrm{S} 10$ a) Graph showing the charge delivered by electrodes of $\mathrm{SrIrO}_{3}$ (blue) and $\mathrm{H}_{2} \mathrm{IrO}_{3}$ (orange) during the potential hold for ICP-OES measurements. b) Percentage of Ir leached during potential hold at $1.55 \mathrm{~V}$ vs $\mathrm{RHE}$ in $1 \mathrm{M} \mathrm{H}_{2} \mathrm{SO}_{4}$ normalized by the BET surface area.

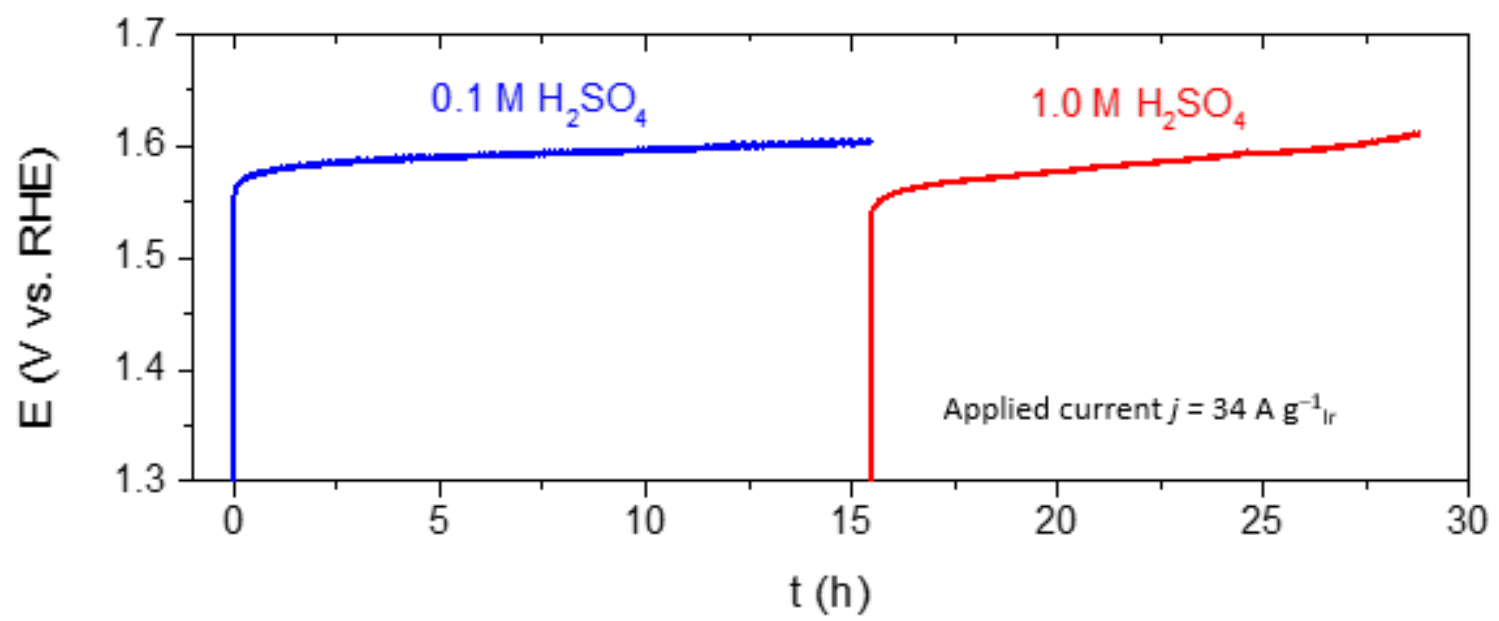

Figure $\mathrm{S} 11$ Electrochemical stability of the $\beta-\mathrm{H}_{2} \mathrm{IrO}_{3}$ catalyst. The electrode was applied with a constant current of $2 \mathrm{~mA} \mathrm{~cm}^{-2}$ oxide in 02 -saturated $0.1 \mathrm{M} \mathrm{H}_{2} \mathrm{SO}_{4}$ solution for 15 hours then in 02 saturated $1.0 \mathrm{M} \mathrm{H}_{2} \mathrm{SO}_{4}$ solution for 14 hours. 

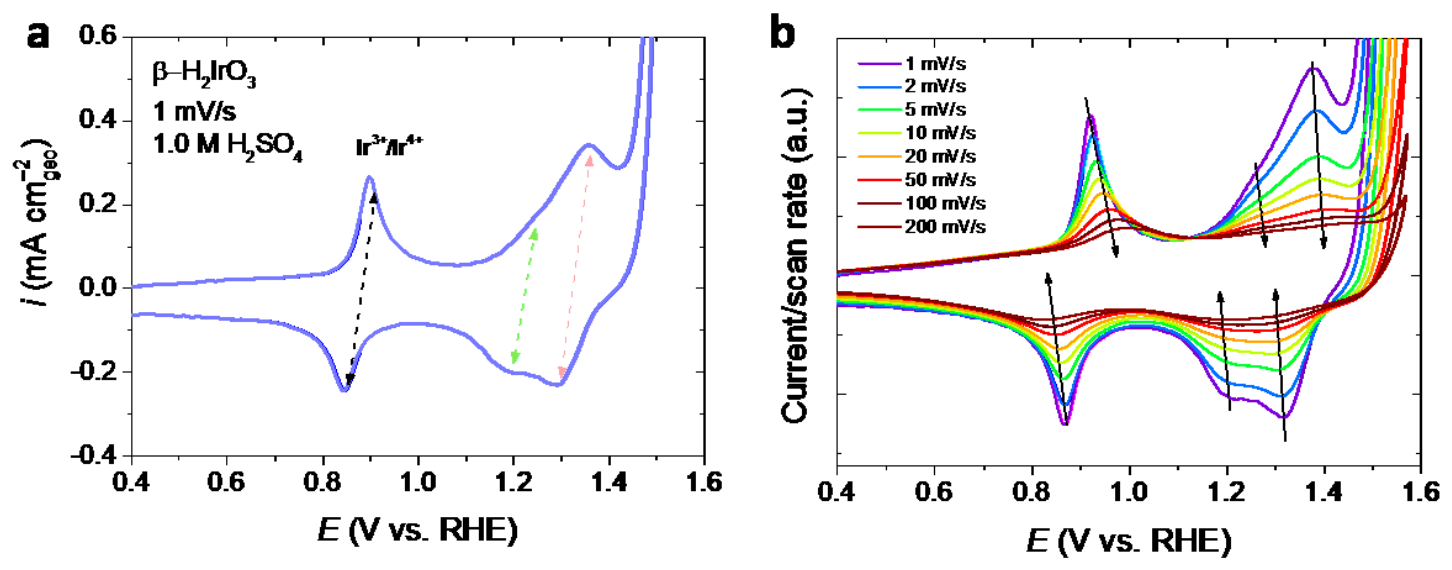

Figure S 12 Cyclic voltammetry showing the capacitive region of $\beta-\mathrm{H}_{2} \mathrm{IrO}_{3}$. (a) $\mathrm{CV}$ at a scan rate of 1 $\mathrm{mV} / \mathrm{s}$ in $1.0 \mathrm{M} \mathrm{Ar-saturated} \mathrm{sulfuric} \mathrm{acid} \mathrm{solution.} \mathrm{(b)} \mathrm{CV} \mathrm{curves} \mathrm{with} \mathrm{the} \mathrm{current} \mathrm{being} \mathrm{normalized}$ by the scan rate. The gradual disappearing of the characteristic redox peaks at high scan rate $(200$ $\mathrm{mV} / \mathrm{s}$ ) suggests a slow dynamics for proton insertion presumably limited by proton bulk diffusion.

Table $\mathrm{S} 1$ Crystallographic data of $\beta-\mathrm{Li}_{2} \mathrm{IrO}_{3}, \beta-\mathrm{Na}_{1.7} \mathrm{IrO}_{3}, \beta-\mathrm{H}_{2} \mathrm{IrO}_{3}$ obtained by refining synchrotron data and $\beta-\mathrm{H}_{\mathrm{x}} \mathrm{IrO}_{3}$ after charging to $1.65 \mathrm{~V}$ vs RHE obtained by refining lab XRD data.

\begin{tabular}{ccccc}
\hline Composition & $\mathrm{a}(\AA)$ & $\mathrm{b}(\AA)$ & $\mathrm{c}(\AA)$ & $\mathrm{Vol}\left(\AA^{3}\right)$ \\
\hline$\beta-\mathrm{Li}_{2} \mathrm{IrO}_{3}$ & $5.91029(5)$ & $8.45734(7)$ & $17.81229(16)$ & $890.353(14)$ \\
$\beta-\mathrm{Na}_{1.7} \mathrm{IrO}_{3}$ & $6.41767(8)$ & $8.95985(10)$ & $18.5988(2)$ & $1069.45(2)$ \\
$\beta-\mathrm{H}_{2} \mathrm{IrO}_{3}$ & $5.39605(7)$ & $9.07170(16)$ & $18.5488(2)$ & $907.99(2)$ \\
$\beta-\mathrm{H}_{\mathrm{x}} \mathrm{IrO}_{3}$ & $5.3660(10)$ & $9.1163(15)$ & $18.314(3)$ & $895.8(3)$ \\
\hline
\end{tabular}


Table S 2 Crystallographic data for $\beta-\mathrm{D}_{1.6} \mathrm{IrO}_{3}$ obtained from Rietveld refinement of NPD data acquired at D20 beamline, Institut Laue Langevin.

\begin{tabular}{|c|c|c|c|c|c|c|}
\hline Atom & $\begin{array}{l}\text { Wyckoff } \\
\text { position }\end{array}$ & $\mathrm{x} / \mathrm{a}$ & $\mathrm{y} / \mathrm{b}$ & $\mathrm{z} / \mathrm{c}$ & Occupancy & $\mathrm{B}\left(\AA^{2}\right)$ \\
\hline Ir & $16 \mathrm{~g}$ & $1 / 8$ & $1 / 8$ & $0.70664(12)$ & 1 & $0.24(4)$ \\
\hline 01 & $16 e$ & $0.8699(8)$ & $1 / 8$ & $1 / 8$ & 1 & $0.55(7)$ \\
\hline 02 & $32 \mathrm{~h}$ & $0.6333(7)$ & $0.3473(2)$ & $0.03850(15)$ & 1 & $0.56(5)$ \\
\hline D1 & $32 \mathrm{~h}$ & $0.2990(7)$ & $0.3673(7)$ & $0.02539(17)$ & $0.551(5)$ & $1.44(14)$ \\
\hline D2 & $32 \mathrm{~h}$ & $0.2627(16)$ & $0.0482(11)$ & $0.1242(10)$ & $0.255(5)$ & $2.7(3)$ \\
\hline \multicolumn{7}{|c|}{$a=5.40106(12) \AA, b=9.0442(2) \AA, c=18.4976(4) \AA$ and $V=903.56(5) \AA^{3} ; \mathrm{R}_{\mathrm{Bragg}}=2.76 \% ; \chi^{2}=48.9$} \\
\hline
\end{tabular}

Table S 3 BET surface area for the different catalysts studied.

\begin{tabular}{cc}
\hline Composition & specific area $\left(\mathrm{m}^{2} / \mathrm{g}\right)$ \\
$\mathrm{RuO}_{2}$ & 7.32 \\
$\mathrm{IrO}_{2}$ & 0.263 \\
$\mathrm{H}_{2} \mathrm{IrO}_{3}$ & 2.4 \\
$\mathrm{SrIrO}_{3}$ & 0.45 \\
$\beta-\mathrm{Li}_{2} \mathrm{IrO}_{3}$ & 0.085 \\
\hline
\end{tabular}

\section{Experimental}

\section{Material preparation}


Synthesis of $\beta-\mathrm{Li}_{2} \mathrm{IrO}_{3}^{2}$ : In the first step, 1 molar equivalent of $\mathrm{Ir}$ or $\mathrm{IrO}_{2}$ is mixed with 0.9 equivalents of $\mathrm{Li}_{2} \mathrm{CO}_{3}$ by grinding with a mortar and pestle until the mixture is homogeneous. The powder is directly inserted into an alumina crucible covered by an alumina top which is brought to $1080^{\circ} \mathrm{C}$ at $3^{\circ} \mathrm{C} / \mathrm{min}$ in a box furnace and kept for 30 hours under air before cooling to room temperature. The resulting powder is composed of a mixture of $\mathrm{IrO}_{2}$ and $\beta-\mathrm{Li}_{2} \mathrm{IrO}_{3}$. The second step is the completion of the reaction by mixing the product of step 1 with 0.15 equivalents of $\mathrm{Li}_{2} \mathrm{CO}_{3}$ by grinding until homogeneous and firing at $1080^{\circ} \mathrm{C}$ at $3^{\circ} \mathrm{C} / \mathrm{min}$ for $30 \mathrm{~h}$ in a covered alumina crucible. The resulting powder is pure $\beta$ - $\mathrm{Li}_{2} \mathrm{IrO}_{3}$.

Preparation of $\beta$ - $\mathrm{Li}_{1} \mathrm{IrO}_{3}, \quad \beta$ - $\mathrm{Li}_{0.5} \mathrm{IrO}_{3}$ and $\beta$-IrO $\mathrm{Ir}_{3}$ in Li-ion battery: All $\beta$ - $\mathrm{Li}_{1} \mathrm{IrO}_{3}, \quad \beta$ - $\mathrm{Li}_{0.5} \mathrm{IrO}_{3}$ and $\beta$-IrO were prepared in Li-ion battery by charging $\beta-\mathrm{Li}_{2} \mathrm{IrO}_{3}$ as cathode material to $4.1 \mathrm{~V}, 4.6 \mathrm{~V}$ and $4.8 \mathrm{~V}$ vs. $\mathrm{Li}+/ \mathrm{Li}$, respectively, in Swagelok-type cells. The cathode materials after different charging states were washed by $\mathrm{DMC}$ repeatedly and dried in vacuum chamber at room temperature $\left(25^{\circ} \mathrm{C}\right)$ and stored in Ar-filled glove box for further usage.

Preparation of $\beta-\mathrm{H}_{2} \mathrm{IrO}_{3}$ through hydrothermal ion exchange: $\beta-\mathrm{Li}_{2} \mathrm{IrO}_{3}(30.1 \mathrm{mg}$ as example) is added to a 1 mol.l-1 solution of $\mathrm{H}_{2} \mathrm{SO}_{4}\left(10 \mathrm{ml}\right.$ as example) and heated to $120^{\circ} \mathrm{C}$ for 36 hours in a Teflonlined steel autoclave. The resulting powder is washed with ultrapure water several times (until pH of wash water is 7) and dried at $55^{\circ} \mathrm{C}$.

\section{Electrochemistry measurements:}

Working electrode preparation: Electrodes were prepared by drop-casting ink containing oxide catalyst powder on a round glassy carbon electrode (5 $\mathrm{mm}$ diameter) or a large glassy carbon plate $\left(2 \times 2 \mathrm{~cm}^{2}\right) \cdot{ }^{3}$ The glassy carbon electrode was loaded with $0.5 \mathrm{mg}_{\text {catalyst }} \mathrm{cm}^{-2}$ disk and a mass ratio of 5:1:1 of Ir-oxide catalyst to acetylene black carbon to Nafion ${ }^{\circledR}$. Oxygen evolution reaction (OER) measurements were performed using rotating disk electrode (RDE) on a biologic MPG-30 potentiostat (PINE Inc, US). The OER activities of different Ir-based catalysts were evaluated by the

RDE experiments in a three-electrode configuration. The glassy carbon electrode loaded with catalyst is used as working electrode, and a $\mathrm{KCl}$-saturated $\mathrm{Ag} / \mathrm{AgCl}$ reference electrode and a $\mathrm{Pt}$ 
wire were adopted as reference electrode (RE) and counter electrode (CE), respectively. The $\mathrm{Ag} / \mathrm{AgCl}$ reference electrode is calibrated by using a reversible hydrogen reference electrode (HydroFlex®, from Gaskatel, Germany) before and after each experiment. Potentials were then converted to the RHE scale. A scan rate of $10 \mathrm{mV} / \mathrm{s}$ was used for all cyclic voltammetry (CV) and rotation was set to $1600 \mathrm{rpm}$. Oxygen was bubbled into the electrolyte before the $\mathrm{CV}$ and potentiostatic measurements of OER activity. CVs scanned in broad potential ranges between 0.3 to $1.6 \mathrm{~V}$ vs. RHE were measured in Ar-saturated sulfuric acid solutions. $\mathrm{H}_{2} \mathrm{SO}_{4}$ (96-98\%, SigmaAldrich) solutions with different concentrations were prepared using Milli-Q® ultrapure water. All electrochemical measurements were conducted at room temperature $\left(25^{\circ} \mathrm{C}\right)$.

OER activity measurement: Electrochemical stability of the $\beta-\mathrm{H}_{2} \mathrm{IrO}_{3}$ catalyst was evaluated by both long-term CV cycles and chronopotentiometry. An accelerated degradation test (ADT) was carried out by subjecting the catalyst to $300 \mathrm{CV}$ cycles at a scan rate of $10 \mathrm{mV} / \mathrm{s}$ in Ar-saturated $1.0 \mathrm{M} \mathrm{H}_{2} \mathrm{SO}_{4}$ solution between 0.4 to $1.6 \mathrm{~V}$ vs. RHE.

Ir dissolution during OER: Ir dissolution during OER for different Ir-based catalysts, including $\mathrm{SrIrO}_{3}$ and $\beta-\mathrm{H}_{2+\mathrm{x}} \mathrm{IrO}_{3}$, was compared by chronoamperometry using inductively coupled plasma optical emission spectrometry (ICP-OES) on a ThermoFisher iCAP 6000 device. Chronoamperometry was conducted by holding the electrode at $1.55 \mathrm{~V}$ vs. RHE $\left(\eta_{O E R}=320 \mathrm{mV}\right)$ in a $40 \mathrm{ml}$ of $1.0 \mathrm{M} \mathrm{H}_{2} \mathrm{SO}_{4}$ solution continuously for 50 hours.

Assembly of Li-ion battery: Li-ion battery was assembled in glovebox in Ar atmosphere. The assynthesized $\beta-\mathrm{Li}_{2} \mathrm{IrO}_{3}$ powder was used as active material, and mixed with $5 \%$ acetylene black carbon in a mortar. The mixture was dried in a Buchi oven at $80{ }^{\circ} \mathrm{C}$ under vacuum overnight prior to use. LP-100 was used as electrolyte, in which $1.0 \mathrm{M} \mathrm{LiPF}_{6}$ was dissolved in EC/PC/DMC in a 1:1:3 weight ratio. Li-ion batteries were assembled using Swagelok-type cells with glass fiber (Whatman, GF/D) separator and Li metal as counter electrode. The assembled Li-ion cells were galvanostatically cycled using a VMP potentiostat system (Biologic S.A., Claix, France).

\section{Physical characterizations:}


Diffraction measurements: Operando and ex situ XRD measurements were performed in a BRUKER D8 Advance diffractometer with $\mathrm{Cu}$ K $\alpha$ radiation $\left(\lambda_{\mathrm{K} \alpha 1}=1.54056 \AA, \lambda_{\mathrm{K} \alpha 2}=1.54439 \AA\right)$ using a home designed cell. A three-electrode configuration is adopted using carbon paper loaded with $\sim 5-8 \mathrm{mg}$ $\mathrm{cm}^{-2}$ geo of $\beta-\mathrm{H}_{2} \mathrm{IrO}_{3}$ catalyst as working electrode, a $\mathrm{KCl}$-saturated $\mathrm{Ag} / \mathrm{AgCl}$ reference electrode and a Pt wire as counter electrode. For the pristine material, the synchrotron XRD pattern was measured at ALBA synchrotron's MSPD beamline ${ }^{4}$ using a $0.3 \mathrm{~mm}$ Kapton capillary with a wavelength of $0.41226 \AA$ A. The Neutron Powder Diffraction (NPD) measurements were performed on the D20 beamline at the Institut Laue Langevin in Grenoble (France) using a Vanadium can with a wavelength of $1.5419 \AA$.

The composition obtained by the nutron refinement is lower than expected which is related to the fact that the measurement was performed on a deuterated sample and not a protonated one for better resolution. However, the diffusion of deuterium seems slower than that of protons as can be observed from the electrochemical data in the Figure $S^{\prime} 1$. This can lead to a lower amount of deuterium in the structure and explains the discrepancy between the NPD refinement and the result from TGA.

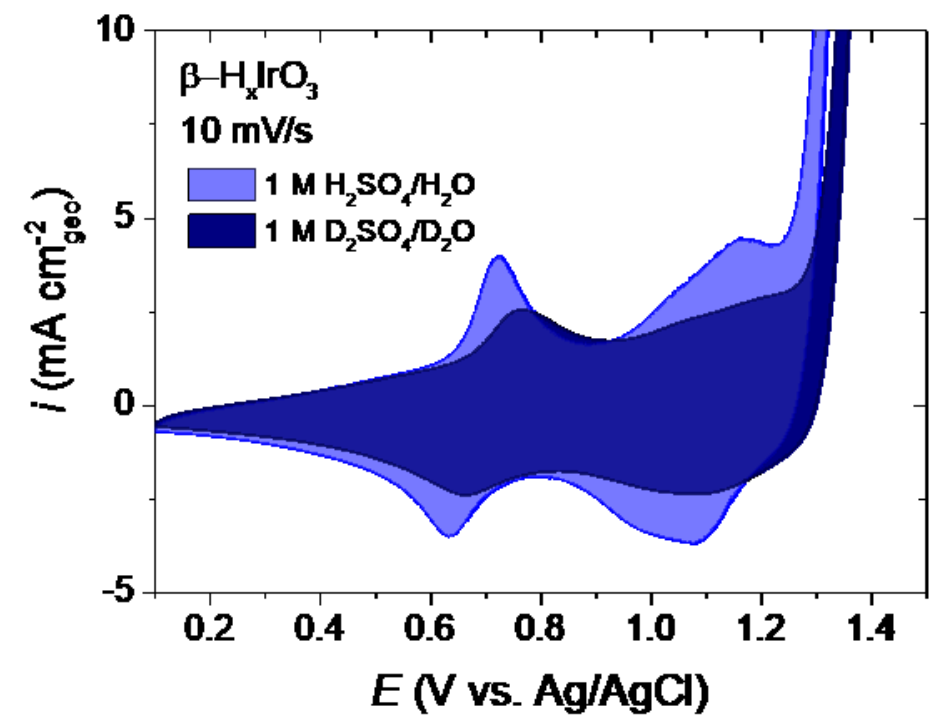

Figure $\mathrm{S}^{\prime} 1 \mathrm{H} / \mathrm{D}$ isotope effect for the OER activity and surface redox properties of $\beta-\mathrm{H}_{2} \mathrm{IrO}_{3}$. CVs conducted in $1.0 \mathrm{M} \mathrm{H}_{2} \mathrm{SO}_{4} / \mathrm{H}_{2} \mathrm{O}$ and $\mathrm{D}_{2} \mathrm{SO}_{4} / \mathrm{D}_{2} \mathrm{O}$ solutions are compared. The slow deuterium 
transfer kinetics in $\mathrm{D}_{2} \mathrm{SO}_{4} / \mathrm{D}_{2} \mathrm{O}$ solution suppresses the OER activity, as well as the redox of Ir for $\beta$ $\mathrm{H}_{2} \mathrm{IrO}_{3}$.

In contrast to crystalline $\mathrm{IrO}_{2}$ (see Figure $\mathrm{S} 5$, and reference ${ }^{5}$ ), the hydrated $\beta-\mathrm{H}_{2} \mathrm{IrO}_{3}$ phase shows three reversible redox peaks at $0.9,1.25$ and $1.35 \mathrm{~V} v$ s. RHE prior to reach the OER. These characteristic redox peaks is largely affected by the proton intercalation/deintercalation kinetics, which gradually diminish at higher scan rate.

Operando XAS: Operando XAS measurements at the $\mathrm{Ir} \mathrm{L}_{3}$-edge were performed in transmission mode at the ROCK beamline ${ }^{6}$ of synchrotron SOLEIL (France). A Si (111) channel-cut quick-XAS monochromator with an energy resolution of $2 \mathrm{eV}$ at $11 \mathrm{keV}$ was used. The intensity of the monochromatic X-ray beam was measured by three consecutive ionization detectors. The in situ 3electrodes cell (Figure S 4) was placed between the first and the second ionization chambers. Operando XAS spectra were collected continuously at a rate of $2 \mathrm{~Hz}$ and averaged out over periods of 20 seconds. The energy calibration was established with simultaneous absorption measurements on an Ir metal foil placed between the second and the third ionization chamber. The data was treated using the Demeter package for energy calibration and normalization. The normalized spectra were then globally analyzed with Principal Component Analysis (PCA) ${ }^{8}$ in order to individuate the orthogonal components able to describe the whole evolution during cycling. The number of principal components was then used as basis for Multivariate Curve ResolutionAlternating Least Squares (MCR-ALS) analysis. ${ }^{9}$ The WL energy position was obtained as the value for which the first derivative of the XANES portion of each spectrum is null. The WL intensity was obtained by fitting the XANES spectra using an Arctan function for the step and a Gaussian function to fit the WL (see Figure S 4).

Solid-state NMR (ssNMR): ssNMR spectra were recorded on a Bruker 4.7 T Avance III spectrometer mounted with a $1.3 \mathrm{~mm}$ double-resonance probehead tuned to ${ }^{1} \mathrm{H}$ at $200 \mathrm{MHz}$ and ${ }^{7} \mathrm{Li}$ at $77.8 \mathrm{MHz}$. The $1.3 \mathrm{~mm}$ rotor, packed with $\beta-\mathrm{Li}_{2} \mathrm{IrO}_{3}$ or $\beta-\mathrm{H}_{2} \mathrm{IrO}_{3}$, was spinning at a $64 \mathrm{kHz}$ MAS rate under nitrogen at room temperature, with no temperature regulation, assuming that the internal rotor temperature is around $60-70^{\circ} \mathrm{C}$ due to friction effects. The chemical shifts were referenced at 0 
ppm with respect to TMS for ${ }^{1} \mathrm{H}$ and $1 \mathrm{M} \mathrm{LiCl}$ for ${ }^{7} \mathrm{Li}$, and the $\mathrm{RF}$ field strength was set to $250 \mathrm{kHz}$ for ${ }^{7} \mathrm{Li}$ and $287 \mathrm{kHz}$ for ${ }^{1} \mathrm{H}$. All 1D spectra were obtained with a rotor synchronized Hahn echo sequence, with a total echo time of 2 rotor periods (31.25 $\mu \mathrm{s})$. The 2D EXSY and RFDR sequence have been described in previous works. ${ }^{10}$

For ${ }^{7} \mathrm{Li} \mathrm{NMR}$ on $\beta-\mathrm{Li}_{2} \mathrm{IrO}_{3}$ (see Figure S 9) two sites of nearly equal intensities (49/51\%) were detected with very weak sidebands, as expected in the XRD structure. We account for the observed shifts with the model for paramagnetic Fermi contact (FC) shifts developed by Grey et al.,11 for lithium oxides containing paramagnetic metals with octahedral geometry. The observed shifts can be interpreted using the sum of the individual contributions of all paramagnetic Ir-O-Li bonds, each bond contributing to a positive or a negative shift depending on the $\mathrm{Ir}-\mathrm{O}-\mathrm{Li}$ bond angle and the electronic configuration. The FC shift is expected to be dominant here, as the chemical shift range is negligible compared to the FC shift. Assuming a low spin configuration, Grey's model indicates that the $90^{\circ} \mathrm{Ir}-\mathrm{O}-\mathrm{Li}$ bonds will give rise to a positive FC shift through delocalization, while the $180^{\circ} \mathrm{Ir}-\mathrm{O}-\mathrm{Li}$ is expected to lead to a negative shift on ${ }^{7} \mathrm{Li}$ by a polarization mechanism. Therefore, as Li1 is bound to four O-Ir with a $180^{\circ}$ angle and four at $90^{\circ}$, while Li2 is bound to 2 and 50 -Ir at $180^{\circ}$ and $90^{\circ}$, respectively, we expect Li1 to have the lowest shift. Therefore, we assigned the $261 \mathrm{ppm}$ peak to $\mathrm{Li} 2$ and the peak at $86 \mathrm{ppm}$ to Li1. The longitudinal relaxation times $\left(\mathrm{T}_{1}\right)$ were measured at 49 and $107 \mathrm{~ms}$ for Li2 and Li1, respectively. Therefore, the 2D RFDR experiment is possible and clearly confirms the proximity between the two lithium sites which belong to the same phase. The rather long T1 allowed us to run a 2D-EXSY experiment, and for a 5 ms mixing time, we found a weak cross-peak indicating magnetization exchange. Previous experiments, such as those run by Messinger et al. showed that spin diffusion at such high MAS rate is expected to quench significant spin diffusion, and therefore, we can confirm that chemical exchange occur between the two sites. The plot of the ratio between the areas of the cross peak and of the diagonal peak has a linear dependence with the mixing time (from 5 to $50 \mathrm{~ms}$ ), allowing us to retrieve the rather slow exchange rate constant at $1.19 \mathrm{~s}^{-1}$.

For ${ }^{1} \mathrm{H}$ NMR on $\beta-\mathrm{H}_{2} \mathrm{IrO}_{3}$ (see Figure S 2), the 1D Hahn echo spectrum displays many sites, and a 2D Hahn echo was used to distinguish the different sites based on $\mathrm{T}_{2}$ variations leading to 
different linewidths in the indirect dimension. A minimum of 9 sites were necessary to model Figure S 2 a) correctly. As the adjacent $\mathrm{H} 1$ and $\mathrm{H} 2$ sites are unlikely to be protonated at the same time due to their occupancies, we expect the shortest $\mathrm{H}-\mathrm{H}$ distance to be around $2.7 \AA$, which would give rise to a dipolar coupling of roughly $6 \mathrm{kHz}$ which should be averaged by ultra-fast MAS. The longitudinal relaxation times $\left(\mathrm{T}_{1}\right)$ varied between $52 \mathrm{~ms}$ for the left hand side of the spectrum to $164 \mathrm{~ms}$ for the peaks in the middle and $332 \mathrm{~ms}$ for the two peaks on the right hand side. The 2D RFDR shows that all sites are correlated to each other, and therefore belong to the same homogeneous- phase (Figure S $2 \mathrm{~d}$ ). The EXSY experiment shown in e (5 ms) and f (50 ms) both feature cross-peaks between the peaks located in left hand side of the spectrum. Spin diffusion is expected to be reduced by ultra-fast spinning and the relatively long distances between the hydrogen atoms. A faint and nearly undetectable cross-peak between the site at $48 \mathrm{ppm}$ and the peaks on the left is observed (not shown), and confirms that chemical exchange between hydrogen sites is observed but is extremely slow between some of the environments. Precise quantification of the exchange rate was impossible due to the multiplicity of sites and further studies will be needed to fully understand the ${ }^{1} \mathrm{H}$ MAS-NMR spectra.

X-ray photoelectron spectroscopy: Standard XPS measurements (in-house) were performed with a Kratos Axis Ultra spectrometer (monochromatized $\mathrm{Al} \mathrm{K \alpha}$ radiation $h v=1486.6 \mathrm{eV}$ ). The analyzed area of the samples was $300 \mu \mathrm{m} \times 700 \mu \mathrm{m}$. Peaks were recorded with constant pass energy of 20 $\mathrm{eV}$. For the $\mathrm{Ag} 3 d_{5 / 2}$ line, the full width at half maximum (FWHM) was $0.58 \mathrm{eV}$ under the recording conditions. Hard X-ray photoemission spectroscopy (HAXPES) was carried out at the GALAXIES12,13 beamline of SOLEIL synchrotron with $h v=6.9 \mathrm{keV}$ photon energy (third order reflection of the Si(111) double-crystal monochromator). Photoelectrons were analyzed by a SCIENTA EW4000 spectrometer, and the obtained energy resolution from the Au Fermi edge was $0.14 \mathrm{eV}$.

Thermogravimetric analysis coupled with differential scanning calorimetry (TGA-MS): TGA-MS measurements were recorded with a STA 449C Netzsch apparatus under argon by applying a heating rate of $5 \mathrm{~K} \mathrm{~min}^{-1}$ from room temperature to $1000^{\circ} \mathrm{C}$ using around $15-20 \mathrm{mg}$ of material. 
Scanning Electron Microscopy: The morphology of the particles was observed by scanning electron microscopy (SEM) performed in Hitachi S-3400N and FEI Quanta FEG 250 microscopes. Energy dispersive X-ray (EDX) analysis was performed using an Oxford X-Max detector (accelerating voltage: $10 \mathrm{keV}$ ) to evaluate the atomic ratio of $\mathrm{K}$ to Ir.

Brunauer, Emmet and Teller (BET): The specific surface area of each oxide was determined using BET analysis on a Quantachrome ChemBET Pulsar from a singlepoint BET analysis performed after $12 \mathrm{~h}$ outgassing at $150^{\circ} \mathrm{C}$ (Table S1).

Online Mass spectrometry (OMS) gas-analysis: OMS was performed using a HIDEN H1 mass spectrometer system (HIDEN Analytical, UK). A three-neck Swagelok-type cell was used as the reaction container with one neck connecting to the mass spectrometer for gas analysis, two necks sealed by a stainless steel rod and a silicone rubber stopper. $\sim 100 \mathrm{mg}$ of as-prepared $\mathrm{IrO}_{3}$ powder was sealed in the Swagelok cell in the Ar-glovebox. The Swagelok cell was then connected to the HIDEN mass spectrometer through a flexible $1 \mathrm{~m}$ capillary inlet and two porous stainless steel membrane filters ( $\sim 2 \mu \mathrm{m}$ pore diameter, Valco Instruments Co. Inc.) for online gas analysis. $2 \mathrm{ml}$ of Ar-saturated $1 \mathrm{M} \mathrm{H}_{2} \mathrm{SO}_{4}$ solution was injected using a syringe through the silicon stopper into the Swagelok cell. Blank test was conducted by injecting $\mathrm{H}_{2} \mathrm{SO}_{4}$ solution into a sealed Swagelok cell without the $\mathrm{IrO}_{3}$ powder.

1. Massiot, D. et al. Modelling one- and two-dimensional solid-state NMR spectra: Modelling 1D and 2D solid-state NMR spectra. Magnetic Resonance in Chemistry 40, 70-76 (2002).

2. Pearce, P. E. et al. Evidence for anionic redox activity in a tridimensional-ordered Li-rich positive electrode $\beta$-Li2IrO3. Nature Materials 16, 580-586 (2017). 
3. Suntivich, J., Gasteiger, H. A., Yabuuchi, N. \& Shao-Horn, Y. Electrocatalytic Measurement Methodology of Oxide Catalysts Using a Thin-Film Rotating Disk Electrode. Journal of The Electrochemical Society (2010). doi:10.1149/1.3456630

4. Fauth, F. et al. The crystallography stations at the Alba synchrotron. The European Physical Journal Plus 130, 160 (2015).

5. Pfeifer, V. et al. In situ observation of reactive oxygen species forming on oxygen-evolving iridium surfaces. Chemical Science 8, 2143-2149 (2017).

6. Briois, V. et al. ROCK: the new Quick-EXAFS beamline at SOLEIL. Journal of Physics: Conference Series 712, 012149 (2016).

7. Leriche, J. B. et al. An Electrochemical Cell for Operando Study of Lithium Batteries Using Synchrotron Radiation. Journal of The Electrochemical Society 157, A606-A610 (2010).

8. De Juan, A., Jaumot, J. \& Tauler, R. Multivariate Curve Resolution (MCR). Solving the mixture analysis problem. Analytical Methods 6, 4964-4976 (2014).

9. Massart, D. L. et al. Handbook of Chemometrics and Qualimetrics: Part A. 20, (Elsevier Science, 1997).

10. Messinger, R. J. et al. Revealing Defects in Crystalline Lithium-Ion Battery Electrodes by Solid-State NMR: Applications to LiVPO4F. Chemistry of Materials 27, 5212-5221 (2015).

11. Grey, C. P. \& Dupré, N. NMR Studies of Cathode Materials for Lithium-Ion Rechargeable Batteries. Chem. Rev. 104, 4493-4512 (2004).

12. Rueff, J.-P. et al. The GALAXIES beamline at the SOLEIL synchrotron: inelastic X-ray scattering and photoelectron spectroscopy in the hard X-ray range. Journal of Synchrotron Radiation 22, 175-179 (2015). 
13. Rueff, J.-P., Rault, J. E., Ablett, J. M., Utsumi, Y. \& Céolin, D. HAXPES for Materials Science at the GALAXIES Beamline. Synchrotron Radiation News 31, 4-9 (2018). 
